\title{
The electro-mechanical tensile properties of an engineered cementitious composite
}

\section{Danah Saraireh}

School of Energy, Geoscience, Infrastructure and Society, Institute for Infrastructure and Environment, Heriot-Watt University, Edinburgh, Scotland, UK

\section{Benny Suryanto}

School of Energy, Geoscience, Infrastructure and Society, Institute for Infrastructure and Environment, Heriot-Watt University, Edinburgh, Scotland, UK (Orcid:0000-0002-3979-9994) (corresponding author: b.suryanto@hw.ac.uk)

\author{
William John McCarter \\ School of Energy, Geoscience, Infrastructure and Society, Institute for \\ Infrastructure and Environment, Heriot-Watt University, Edinburgh, \\ Scotland, UK (Orcid:0000-0002-1949-2856) \\ Steven Walls \\ School of Energy, Geoscience, Infrastructure and Society, Institute for \\ Infrastructure and Environment, Heriot-Watt University, Edinburgh, \\ Scotland, UK
}

The influence of ongoing cement hydration and multiple microcrack formation on the electrical impedance of an engineered cementitious composite (ECC) is presented. Impedance measurements were obtained over the frequency range $20 \mathrm{~Hz}-1 \mathrm{MHz}$ and displayed in the Nyquist format. In addition, the permittivity and conductivity were de-embedded from the measured impedance and presented in both time and frequency domains to elucidate the nature of conduction and polarisation processes. It was found that, over a curing period of 90 days, the ECC displayed a classic impedance response. Both conductivity and relative permittivity were found to be frequency dependent due to bulk relaxation processes operating within the composite. Tensile straining was shown to result in a detectable change in the impedance response, but retained a similar overall profile. When presented in the frequency domain, a downward displacement in both conductivity and relative permittivity profiles was evident with increasing tensile strain. It is shown that the relative permittivity at the high-frequency end could be exploited as a potentially useful indicator for strain/damage detection. The influence of microcracking on the piezo-resistive response of the composite is discussed based on crack patterns obtained from both visual observations and digital image correlation.

\begin{tabular}{|c|c|}
\hline \multicolumn{2}{|c|}{ Notation } \\
\hline$F_{28}$ & 28-day compressive strength (50 mm cube) \\
\hline$F_{90}$ & 90-day compressive strength ( $50 \mathrm{~mm}$ cube) \\
\hline$F$ & tensile stress (MPa) \\
\hline$f$ & frequency $(\mathrm{Hz})$ \\
\hline$f_{\mathrm{c}}$ & cusp-point frequency $(\mathrm{Hz})$ \\
\hline$f_{\text {cr }}$ & first crack tensile stress (MPa) \\
\hline$f_{\mathrm{tu}}$ & tensile strength (MPa) \\
\hline$g_{\mathrm{db}}$ & $\begin{array}{l}\text { geometrical constant for dogbone-shaped specimens } \\
(=245.28 / \mathrm{m})\end{array}$ \\
\hline$g_{\mathrm{p}}$ & $\begin{array}{l}\text { geometrical constant for prism specimens } \\
(=88.48 / \mathrm{m})\end{array}$ \\
\hline$R_{\mathrm{db}, 28}$ & $\begin{array}{l}\text { 28-day electrical resistance for dogbone-shaped } \\
\text { specimen }(\Omega)\end{array}$ \\
\hline$R_{\mathrm{p}, 28}$ & 28-day electrical resistance for prism specimen $(\Omega)$ \\
\hline$Z(\omega)$ & electrical impedance $(\Omega)$ \\
\hline$Z^{\prime}(\omega)$ & resistive (real) component of impedance $(\Omega)$ \\
\hline$Z^{\prime \prime}(\omega)$ & reactive (imaginary) component of impedance $(\Omega)$ \\
\hline$\varepsilon_{\mathrm{t}}$ & tensile strain after start of test \\
\hline$\varepsilon_{\mathrm{tu}}$ & tensile strain capacity \\
\hline$\kappa_{\mathrm{O}}$ & permittivity of free space $\left(8.854 \times 10^{-12} \mathrm{~F} / \mathrm{m}\right)$ \\
\hline$\kappa_{\mathrm{cr}}$ & average relative permittivity of microcracks \\
\hline$\kappa_{\mathrm{r}}^{\prime}(\omega)$ & relative permittivity \\
\hline$\kappa_{\mathrm{r}, \mathrm{i}}$ & $\begin{array}{l}\text { initial bulk relative permittivity of composite } \\
\text { (at } \varepsilon_{\mathrm{t}}=0 \text { ) }\end{array}$ \\
\hline$\kappa_{\mathrm{r}, \mathrm{t}}$ & $\begin{array}{l}\text { bulk relative permittivity of composite at strain } \varepsilon_{\mathrm{t}} \\
\text { after start of test }\end{array}$ \\
\hline$\rho(\omega)$ & bulk resistivity $(\Omega . m)$ \\
\hline$\rho_{28}$ & 28 -day electrical resistivity $(\Omega . m)$ \\
\hline
\end{tabular}

$\begin{array}{ll}\rho_{\mathrm{i}} & \left.\text { initial bulk resistivity (at } \varepsilon_{\mathrm{t}}=0\right)(\Omega . \mathrm{m}) \\ \rho_{\mathrm{t}} & \text { bulk resistivity at strain } \varepsilon_{\mathrm{t}} \text { after start of test }(\Omega . \mathrm{m}) \\ \sigma(\omega) & \text { bulk conductivity }(\mathrm{S} / \mathrm{m}) \\ \phi_{\mathrm{r}, \mathrm{i}} & \text { initial volume at start of test } \\ \phi_{\mathrm{cr}} & \text { volume fraction of microcracks at strain } \varepsilon_{\mathrm{t}} \\ \phi_{\mathrm{r}, \mathrm{t}} & \text { total volume at strain } \varepsilon_{\mathrm{t}} \text { after start of test } \\ \omega & \text { angular frequency }\end{array}$

\section{Introduction}

Concrete is the most widely used construction material, with a large proportion of infrastructure worldwide built using concrete in one form or another. While most key infrastructure is designed for an intended working life of at least 100 years, premature deterioration remains commonplace (Kim et al., 2016; Li et al., 2009). Although some deterioration may not have a direct implication on structural integrity, immediate repair may be required so as not to impair in-service performance (Frangopol et al., 2017). The earlier any deterioration is detected, the earlier appropriate remedial measures can be taken, thereby avoiding the need for costly repairs at a later stage (McCarter et al., 2017; Pines and Aktan, 2002). With the ever-increasing amount of infrastructure around the world and the continual deterioration of existing infrastructure, it is expected that structural inspection and maintenance will have an increasing role to play for the foreseeable future.

It is common practice to undertake periodic visual inspections to enable the effective management and maintenance of 
infrastructure (Omar and Nehdi, 2018; Pines and Aktan, 2002); however, this requires direct site visits by qualified engineers at predetermined times during the life of a structure (HE, 2017). While visual inspection is relatively straightforward to undertake and allows evidence to be gathered directly on site, it only provides a snapshot of information in time - it is the change in condition over time that needs to be assessed so as to provide a reliable assessment of structural health (Choi et al., 2004; Hedegaard et al., 2017; Kim et al., 2018). A further limitation of visual inspection is that some damage may not be readily visible, thereby remaining undetected until advanced stages, which may involve costly repairs. A number of automated structural health monitoring systems have been developed to mitigate the shortcomings of traditional on-site inspections, with some already implemented in real structures and bridges (Abé and Fujino, 2017; Agdas et al., 2015; Lynch et al., 2017; Soga, 2018; Spencer Jr et al., 2017). Such systems typically require the installation of an extensive network of surface-mounted or embedded sensors and monitoring of their responses over time. A similar approach was employed in the work presented here, although the concrete itself was used as the sensor. Developments in this field include moisture sensors (McCarter et al., 2012), weigh-in-motion and traffic sensors (Han et al., 2011; Shi and Chung, 1999) and strain/damage sensors (Azhari and Banthia, 2012; Yoo et al., 2019). While the sensing capabilities of cement-based strain/damage sensors have been well documented, they may only be able to be employed under limited damage levels as the relationship between damage and strain increases non-linearly after cracking.

Recently, damage-tolerant cement-based materials known as engineered cementitious composite (ECCs) have been identified as potential damage sensors (Hou, 2008; Hou and Lynch, 2005; Lin et al., 2011; Ranade et al., 2014). The damage-tolerant property of ECCs originates primarily from their ability to exhibit multiple fine cracks when subjected to tensile stresses beyond the elastic range, generally displaying tensile strain hardening behaviour with a tensile capacity of the order of a few percent and an average crack width under $100 \mu \mathrm{m}$ at maximum strain (Chen et al., 2018; Frank et al., 2018; Lee et al., 2018; Li, 2008; Ma et al., 2019; Suryanto et al., 2015). This is different from ordinary concrete and fibre-reinforced concrete, which generally fail locally due to a single crack. With regard to damage sensing, work has predominantly focused on the piezo-resistive properties of ECCs. Hou (2008) employed the four-point measurement technique to study the piezo-resistivity of a standard ECC mix under both DC and AC currents, with the latter applied at $5 \mathrm{kHz}$. They demonstrated that the composite displayed a quasi-linear piezo-resistive response during strain hardening resulting from the formation of multiple microcracks. Hou and Lynch (2005) further studied the piezo-resistive response of ECC mixes containing steel and carbon fibre using four-point DC measurements. They showed that the ECCs displayed a linear relationship between the change in resistivity and tensile strain, and found that these ECCs were less sensitive to mechanical strain due to the presence of crack-bridging conductive fibres. To minimise bridging effects, Lin et al. (2011) added carbon black to the standard ECC mix to increase the contrast of the composite resistivity before and after cracking. The four-point AC measurement technique was employed, with measurements undertaken at $100 \mathrm{~Hz}$. It was found that the sensitivity of the composite to cracking improved. Employing the two-point method and a constant AC current of $1 \mathrm{kHz}$, Ranade et al. (2014) tested moderate- and high-volume fly ash (FA) ECC mixes with different microcrack characteristics. It was found that, although the high-volume FA mix exhibited a greater number of microcracks, it exhibited less sensitivity to cracking than the moderate-volume FA mix due to its smaller microcrack widths.

To date, much work has focused on the piezo-resistive properties of ECCs using DC and fixed-frequency AC resistivity measurements. Little attention has been directed towards investigating the electrical properties of ECC over a wide frequency spectrum. When subjected to $\mathrm{AC}$, porous materials such as ECCs can be expected to display both conductive and capacitive behaviour - the former due primarily to ionic conduction processes and the latter due to polarisation processes operating within the material (Suryanto et al., 2016, 2018a). The measurement of both quantities could provide more detailed information with regard to the strain/damage sensing capabilities of ECCs. In addition to mechanical loading, it is anticipated that the electrical properties of the ECCs are also influenced by cement hydration, but this aspect has been overlooked in prior studies. These aspects are addressed in this work.

\section{Experimental programme}

\section{Materials and mix proportions}

The mix proportions for the ECC used in this experimental programme are provided in Table 1. The binder comprised a blend of CEM I $52.5 \mathrm{~N}$ Portland cement according to BS EN 197-1:2011 (BSI, 2011) and fine FA (Superpozz SV80, supplied by ScotAsh Ltd) at a cement/FA ratio of $1: 1.8$. To improve the dimensional stability of the mix, fine silica sand with a mean particle size of $120 \mu \mathrm{m}$ was added at a sand/cement ratio $0.6: 1$ by mass; this particle size and amount were considered to ensure that the matrix toughness was low enough to allow tensile strain hardening behaviour. A typical oxide analysis of these materials is presented in Table 2. The water/binder ratio was set at a relatively low value $(0.28)$ to produce a mix with adequate viscosity for fibre dispersion. The only fibres incorporated into the mix were Kuralon K-II REC15 polyvinyl alcohol (PVA) fibres, which have been specifically developed for use in ECCs by Kuraray Japan. The fibres had an average length of $12 \mathrm{~mm}$, diameter of $39 \mu \mathrm{m}$ 
Table 1. ECC mix proportions

\begin{tabular}{lcccc} 
Cement: $\mathbf{k g} / \mathbf{m}^{\mathbf{3}}$ & FA: $\mathbf{k g} / \mathbf{m}^{\mathbf{3}}$ & Silica sand: $\mathbf{k g} / \mathbf{m}^{\mathbf{3}}$ & HRWR: $\mathbf{k g} / \mathbf{m}^{\mathbf{3}}$ & PVA fibres: $\mathbf{k g} / \mathbf{m}^{\mathbf{3}}$ \\
\hline 454 & 818 & 273 & 4.54 & $26(2 \%$ by vol.)
\end{tabular}

Table 2. Oxide analysis and physical properties of materials

$\begin{array}{llll} & & & \text { Silica } \\ & \text { Cement } & \text { FA } & \text { sand } \\ \text { Chemical analysis: } \mathrm{wt}^{2} \% & & & \\ \text { Silicon dioxide }\left(\mathrm{SiO}_{2}\right) & 19.9 & 52.7 & 98.8 \\ \text { Aluminium oxide }\left(\mathrm{Al}_{2} \mathrm{O}_{3}\right) & 4.8 & 26.6 & 0.21 \\ \text { Ferric oxide }\left(\mathrm{Fe}_{2} \mathrm{O}_{3}\right) & 3.1 & 5.6 & 0.09 \\ \text { Potassium oxide }\left(\mathrm{K}_{2} \mathrm{O}\right) & \mathrm{ND}^{\mathrm{a}} & \mathrm{ND} & 0.03 \\ \text { Calcium oxide }(\mathrm{CaO}) & 62.4 & 2.4 & \mathrm{ND} \\ \text { Magnesium oxide }(\mathrm{MgO}) & 2.2 & 1.2 & \mathrm{ND} \\ \text { Sodium oxide }\left(\mathrm{Na}_{2} \mathrm{O}\right) \text { equivalent } & 0.54 & 1.7 & \mathrm{ND} \\ \text { Sulfur trioxide }\left(\mathrm{SO}_{3}\right) & 3.0 & 0.3 & \mathrm{ND} \\ \text { Free calcium oxide } & \mathrm{ND} & 0.03 & \mathrm{ND} \\ \text { Total phosphates } & \mathrm{ND} & 0.5 & \mathrm{ND} \\ \text { Loss on ignition } & \mathrm{ND} & <2.0 & 0.14 \\ \text { Physical properties } & & & \\ \text { Specific gravity } & 3.15 & 2.20 & 2.65 \\ \text { Surface area: } \mathrm{m}^{2} / \mathrm{kg} & 375 & 1300 & \mathrm{ND} \\ \text { Fineness: \% retained on } 25 \mu \mathrm{m} \text { sieve } & \mathrm{ND} & <25 & \mathrm{ND} \\ \text { Cumulative amount retained: \% } & & & \\ 500 \mu \mathrm{m} & \mathrm{ND} & \mathrm{ND} & 0.1 \\ 355 \mu \mathrm{m} & \mathrm{ND} & \mathrm{ND} & 0.5 \\ 250 \mu \mathrm{m} & \mathrm{ND} & \mathrm{ND} & 1.5 \\ 180 \mu \mathrm{m} & \mathrm{ND} & \mathrm{ND} & 6.0 \\ 125 \mu \mathrm{m} & \mathrm{ND} & \mathrm{ND} & 46.0 \\ 90 \mu \mathrm{m} & \mathrm{ND} & \mathrm{ND} & 83.0 \\ 63 \mu \mathrm{m} & \mathrm{ND} & \mathrm{ND} & 96.5 \\ & & & \end{array}$

${ }^{a}$ Not determined

and tensile strength of $1.60 \mathrm{GPa}$, and were supplied with a proprietary oil-based coating agent $(1.2 \%$ by mass $)$ to reduce excessive bonding with the hardened ECC matrix. To aid fibre dispersion and improve the workability of the mix, high-range water-reducing (HRWR) admixture (MasterGlenium ACE499) was added at a dosage of $1 \%$ by cement weight.

\section{Test specimens, fabrication and curing}

A Hobart planetary motion mixer with a capacity of 101 was used to prepare the mix presented in Table 1 in a single batch. In total, 13 specimens were produced, comprising

- three $40 \times 40 \times 160 \mathrm{~mm}$ (long) prismatic specimens (P1-P3) to monitor the influence of continued hydration

- four dogbone-shaped specimens (DB1-DB4) of dimensions in accordance with the recommendations of the Japan Society of Civil Engineers (JSCE, 2008) to determine the mechanical and electrical properties under uniaxial tensile loading

- six $50 \mathrm{~mm}$ cuboidal specimens $(\mathrm{C} 1-\mathrm{C} 6)$ to determine compressive strengths.
The prisms had two $45 \times 65 \times 2 \mathrm{~mm}$ (thick) perforated stainless steel electrodes placed $140 \mathrm{~mm}$ apart (see Figure 1(a)). The electrodes had $10 \mathrm{~mm}$ round holes at a $15 \mathrm{~mm}$ staggered pitch to allow ease of infiltration by the ECC during casting and thereby ensuring intimate bonding (Suryanto et al., 2018b). The dimensions of the dogbone-shaped specimens are shown in Figure 1(b). This figure also shows the electrode configuration employed, comprising two wire electrodes wrapped securely at the opposing ends of the central neck of the specimens. The wire electrodes were covered with several coats of silver-loaded conductive paint to seal any gaps and ensure intimate contact with the specimen.

The prisms were cast into a single-use three-gang polystyrene mould, whereas the dogbone and cube specimens were cast in custom-made plexiglass and three-gang steel moulds, both of which had been treated with a proprietary release agent (Sika Everbuild 206). Immediately after casting, all the specimens were covered with thick cling film and allowed to cure for $24 \mathrm{~h}$. The specimens were then demoulded and stored in a curing tank at $20 \pm 2{ }^{\circ} \mathrm{C}$ until they were required for testing. After 2 weeks, the dogbone-shaped specimens were removed from the curing tank and allowed to dry for $\sim 3 \mathrm{~h}$; the wire electrodes, discussed above, were then attached to the specimens and coated with conductive paint. When the paint was dry, the samples were returned to the tank until required for testing at 28 days.

\section{Test procedures and equipment}

The work undertaken involved the testing of three prisms to study the influence of ongoing cement hydration and the testing of four dogbone-shaped specimens to obtain the electro-mechanical properties of the composite under tensile straining.

\section{Hydration study and compressive strength}

A Keysight E4980AL precision LCR meter was employed to acquire the electrical impedance of prisms P1-P3 over the initial 90 days after casting. The impedance was recorded at 20 spot frequencies per decade over the frequency range $20 \mathrm{~Hz}-1 \mathrm{MHz}$. The LCR meter was operated in voltage drive mode, at a constant signal amplitude of $350 \mathrm{mV}$, and controlled by a desktop computer (PC), which was also used for data acquisition. Communication with the LCR meter was established by means of the built-in USB interface in the LCR, which was accessed by the PC through Keysight IO Library Suite software (version 2017.1). To manage the overall running of the experiment, a customised virtual instrument was developed in the LabView environment (LabView, 2017), 


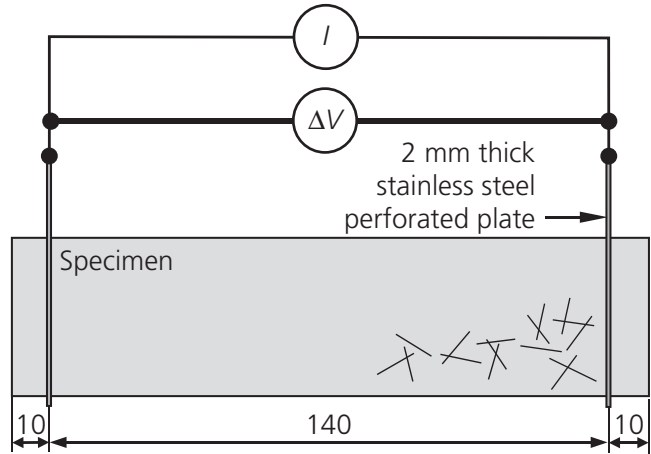

(a)

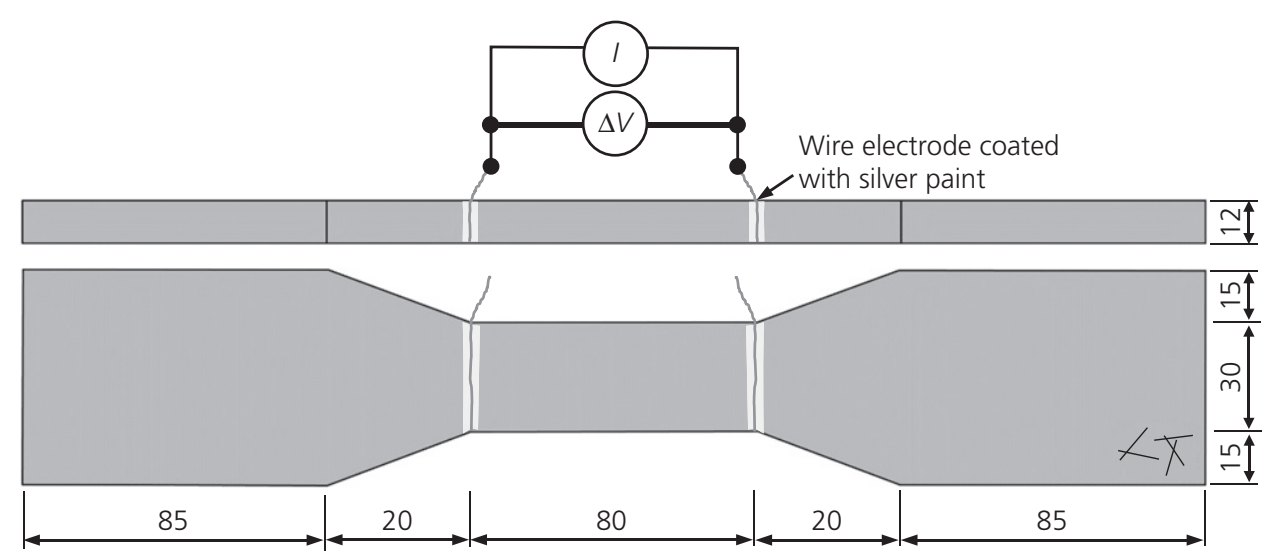

(b)

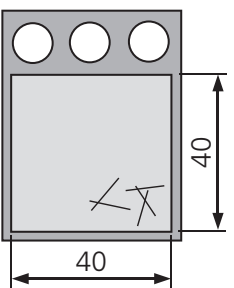

Figure 1. Schematic illustration of testing arrangement for two-point measurements using: (a) embedded perforated plate electrodes; (b) surface-applied (silver-coated) wire electrodes (dimensions in $\mathrm{mm}$ )

which permits full control of the LCR meter. This virtual instrument was also used to process the raw impedance data, present the results in both tabular and graphical forms, and store the processed data in a CSV format for further analysis. In the electrical measurements, four individually screened, short coaxial leads were used. At the time of testing, leads from the high-current and high-potential terminals on the LCR meter were connected to one electrode and the lowcurrent and low-potential terminals to the other, following the two-point configuration (McCarter et al., 2015).

In addition to electrical measurements, the compressive strengths of the ECC were determined from C1-C6 using a $3000 \mathrm{kN}$ Avery-Dennison testing machine under a loading rate of $50 \mathrm{kN} / \mathrm{min}$. The strengths obtained on days 28 and 90 of the curing period ( $F_{28}$ and $F_{90}$, respectively) are listed in Table 3 , together with the tensile strain capacity $\varepsilon_{\mathrm{tu}}$, the first crack strength $f_{\text {cr }}$ and ultimate tensile strength $f_{\text {tu }}$, determined from the dogbone-shaped specimens (DB1-DB4).

\section{Piezo-impedance study}

On the 28th day of curing, tensile testing was performed on specimens DB1-DB4 using a $100 \mathrm{kN} 4206$ Instron machine (see Figure 2(a)). Prior to testing, each specimen was aligned in the machine and clamped at both ends using pneumatic grips. Loading was then performed under a cross-head speed of $0.5 \mathrm{~mm} / \mathrm{min}$. Tensile stresses were determined by dividing load cell readings from the test machine by the cross-sectional area of the narrower (central) section (approximately $30 \times 12 \mathrm{~mm}^{2}$ ), whereas the longitudinal strains within this region were determined from the average of two linear variable differential transducer (LVDT) readings. These LVDTs were attached prior to testing at the bottom end of the bone-neck region, one on each side, through two lightweight plastic

Table 3. Summary of mechanical properties. The coefficients of variation for the results are shown in brackets

\begin{tabular}{|lcccc}
\hline$\varepsilon_{\text {tu }}: \%$ & $\boldsymbol{f}_{\mathrm{cr}}: \mathbf{M P a}$ & $\boldsymbol{f}_{\mathrm{tu}}: \mathbf{M P a}$ & $\boldsymbol{F}_{\mathbf{2 8}}: \mathbf{M P a}$ & $\boldsymbol{F}_{\mathbf{9 0}}: \mathbf{M P a}$ \\
\hline $3.91(19.1 \%)$ & $2.96(10.7 \%)$ & $4.38(10.0 \%)$ & $51.2(1.94 \%)$ & $63.7(4.40 \%)$
\end{tabular}




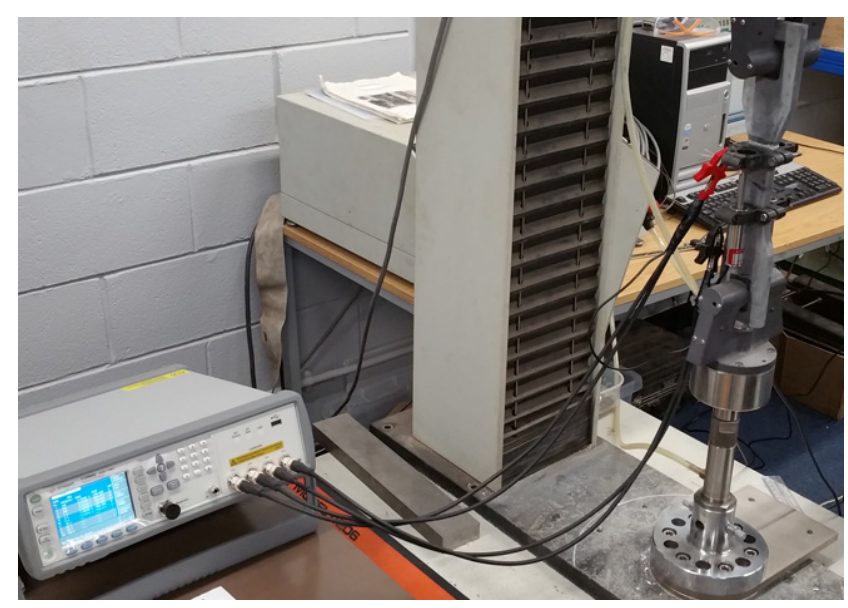

(a)

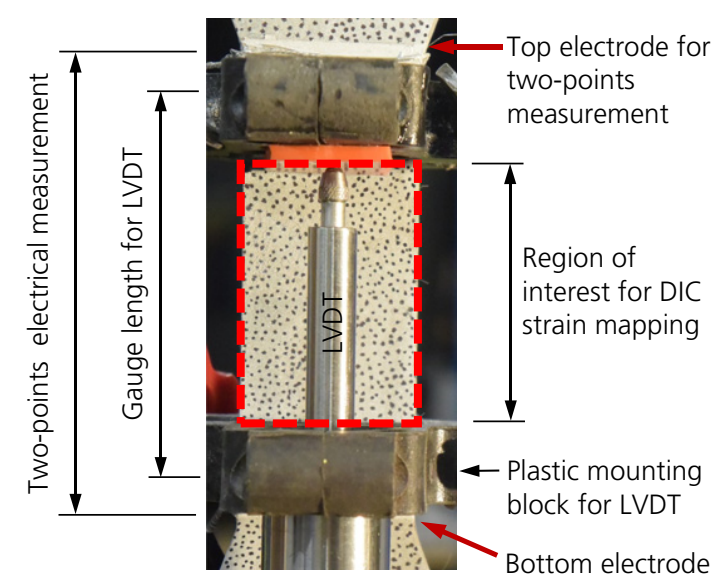

(b)

Figure 2. (a) Test setup; (b) Close-up of measurement during uniaxial tensile testing

mounting blocks (see Figure 2(b)). The gauge length was $\sim 60 \mathrm{~mm}$. All data were recorded using a 16-bit USB data acquisition system at a sampling rate of $1 \mathrm{~s}$.

In addition to the stress and strain readings, simultaneous electrical measurements were undertaken during the loading process to study the influence of multiple microcracking, using the same measurement system employed for testing the prisms. Prior to testing, the pair of wire electrodes at the opposing ends of the central neck of each sample (the distance was $\sim 80 \mathrm{~mm}$ ) were connected to the LCR meter through individually screened coaxial leads, with the connection at the electrodes made using alligator clips (see Figure 2(a)). Electrical measurements were then taken throughout the installation process and during tensile loading at 13 spot frequencies covering five decades $(100 \mathrm{~Hz}, 200 \mathrm{~Hz}, 500 \mathrm{~Hz}$, $1 \mathrm{kHz}, 2 \mathrm{kHz}, 5 \mathrm{kHz}, 10 \mathrm{kHz}, 20 \mathrm{kHz}, 50 \mathrm{kHz}, 100 \mathrm{kHz}$, $200 \mathrm{kHz}, 500 \mathrm{kHz}$ and $1 \mathrm{MHz})$. Low frequencies $(<100 \mathrm{~Hz})$ were omitted from the sweep to minimise the duration of the measurement. This sweep measurement was repeated over a 3-s cycle, facilitating virtually continuous, real-time monitoring during loading, thus minimising the influence of time-dependent effects on the measured impedance.

To provide evidence of microcrack formation, digital images of the front face of specimens DB1-DB4 were taken at $0.1 \mathrm{~mm}$ displacement increments using an 18.4 MP Nikon $1 \mathrm{~J} 4$ mirrorless digital camera, positioned approximately $300 \mathrm{~mm}$ from the specimen. To remove inadvertent camera movement, images were collected remotely using the Nikon wireless mobility utility smartphone application (version 1.2.1). Prior to testing, random black dots were manually drawn on the front surface of specimens, which had been given a thin coat of white acrylic paint (see Figure 2(b)). This was undertaken to give a random pattern with a sharp contrast, thereby facilitating automated strain mapping within the boundary indicated in Figure 2(b). The images were then processed using the digital image correlation (DIC) freeware Ncorr (version 1.2.1) (Blaber et al., 2015; Ncoor, 2018; Suryanto et al., 2017a; Tambusay et al., 2020). In addition to this automated crack mapping, more detailed crack mappings were undertaken manually using ImageJ1 software (Schneider et al., 2012), with the aim of obtaining the number of microcracks and the width of each individual microcrack under various stages of loading.

\section{Data analysis and presentation}

The impedance of a cement-based system $(Z(\omega)$ in $\Omega$ ) subjected to a small-signal sinusoidal electric field at an angular frequency $\omega$ can be represented in a rectangular form as (McCarter and Brousseau, 1990; McCarter et al., 2002; Starrs and McCarter, 1998),

\section{1. $Z(\omega)=Z^{\prime}(\omega)-\mathrm{i} Z^{\prime \prime}(\omega) \Omega$}

where $Z^{\prime}(\omega)$ is the resistive (real) component and $Z^{\prime \prime}(\omega)$ is the reactive (imaginary) component. These two parameters are commonly presented in the Nyquist format, with $Z^{\prime \prime}(\omega)$ plotted against $Z^{\prime}(\omega)$ over a wide frequency range (see Figure 3(a)). At any frequency, the impedance of the cementitious system will result from two superposed phenomena conduction and polarisation, which are respectively quantified by the bulk conductivity $(\sigma(\omega))$ and the relative permittivity $\left(\kappa_{\mathrm{r}}^{\prime}(\omega)\right)$ of the system. Both parameters are generally presented in the frequency domain (see, for example, Figures 3(b) and 3(c)) to investigate the nature of conduction and relaxation processes. These parameters can be de-embedded from the resistive and reactive components through the relationships (McCarter et al., 2004; Suryanto et al., 2016)

2. $\sigma(\omega)=\left(\frac{Z^{\prime}(\omega)}{Z^{\prime}(\omega)^{2}+Z^{\prime \prime}(\omega)^{2}}\right) g_{\mathrm{p}} \mathrm{S} / \mathrm{m}$ 


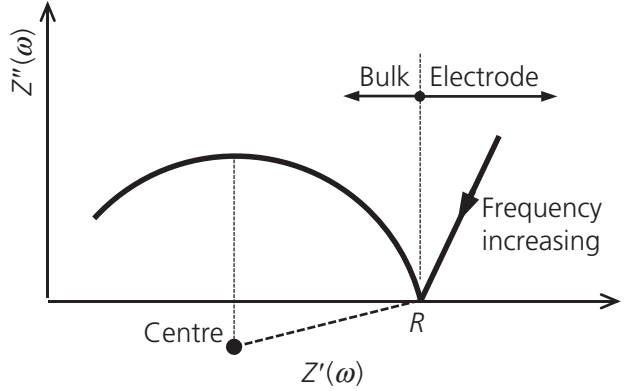

(a)

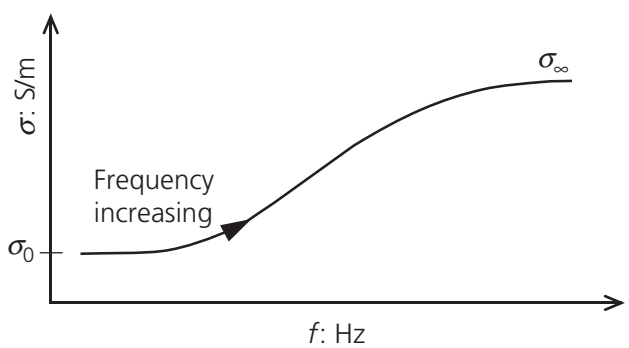

(b)

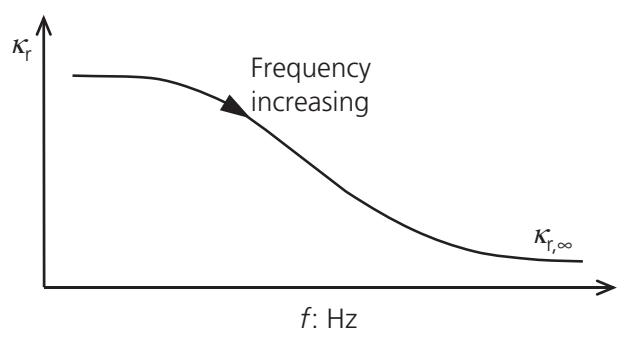

(c)

Figure 3. (a) Schematic illustration of complex impedance response of a cementitious system; (b) Idealised conductivity curve; (c) Idealised relative permittivity curve

3. $\kappa_{\mathrm{r}}^{\prime}(\omega)=\frac{1}{\kappa_{\mathrm{o}} \omega}\left(\frac{Z^{\prime \prime}(\omega)}{Z^{\prime}(\omega)^{2}+Z^{\prime \prime}(\omega)^{2}}\right) g_{\mathrm{p}}$

where $\kappa_{\mathrm{o}}$ is the permittivity of free space $\left(8.854 \times 10^{-12} \mathrm{~F} / \mathrm{m}\right)$ and $g_{\mathrm{p}}$ is a geometrical constant that depends on the electrode geometry and the spatial positioning of the electrodes within the system.

The value of $g_{\mathrm{p}}$ was obtained from previous experiments using solutions of known conductivity, using the same polystyrene mould and perforated stainless steel electrodes as in the test prisms. A value of $g_{\mathrm{p}}=88.48 / \mathrm{m}$ was obtained. For specimens DB1-DB4, the calibration was done by converting the resistance measured from prism specimens P1-P3 at 28 days of curing $\left(R_{\mathrm{p}, 28}\right)$ to resistivity $\left(\rho_{28}\right)$ through the relationship

4. $\rho_{28}=R_{\mathrm{p}, 28} \frac{1}{g_{\mathrm{p}}} \Omega . \mathrm{m}$
Accordingly, the geometrical constant for the dogbone-shaped specimens $\left(g_{\mathrm{db}}\right)$ could be calculated from

5. $g_{\mathrm{db}}=\frac{R_{\mathrm{db}, 28}}{\rho_{28}} / \mathrm{m}$

where $R_{\mathrm{db}, 28}$ is the measured resistance for the dogboneshaped specimen after 28 days curing. The value of $g_{\mathrm{db}}$ was determined to be $245.28 / \mathrm{m}$.

\section{Results and discussion}

Hydration study

\section{Complex impedance response (no tensile loading)}

The impedance spectra for prisms P1-P3 over the initial 90-day period are presented in Nyquist format in Figure 4(a), with frequency increasing from right-to-left across the curve. For reasons of clarity, only every fifth data marker is highlighted on each curve. The solid curves represent the impedance spectrum of $\mathrm{P} 1$, while the dashed curves represent the spectra of $\mathrm{P} 2$ and $\mathrm{P} 3$. It is evident from this figure that there was excellent agreement between the notionally identical prisms, with each response comprising three distinct features.

(a) A small spur at the low-frequency (right-hand) side of the spectrum.

(b) A narrow U-shaped intermediate valley region.

(c) An arc at the high-frequency (left-hand) side which, with the intermediate plateau noted in (b) represents the bulk impedance response.

The low-frequency spur represents the response resulting from polarisation processes at the electrode/specimen interface (McCarter and Brousseau, 1990; McCarter et al., 1988) and constitutes part of a larger arc that would only form at frequencies significantly lower than the lower frequency limit used in the present study (i.e. $<20 \mathrm{~Hz}$ ). The U-shaped intermediate region can be attributed to the presence of unburnt carbon in the FA, the extent of which has been found to have direct proportion to the amount of free carbon content in the FA (McCarter et al., 2004; Suryanto et al., 2017b), which is quantified by its loss on ignition (see Table 2). By presenting the impedance data in Nyquist format, as in Figure 4(a), it is possible to separate the response of the electrodes from that of the bulk material, thereby allowing calculation of the bulk ionic resistance of the composite. This was obtained from the projected intercept of the low-frequency end of the bulk arc with the real axis. By doing so, the bulk resistance at 7 days was evaluated to be $\sim 1.1 \mathrm{k} \Omega$, increasing to $\sim 2.9 \mathrm{k} \Omega$ at 28 days, $\sim 5.1 \mathrm{k} \Omega$ at 56 days and $\sim 7.3 \mathrm{k} \Omega$ at 90 days. The progressive increase in bulk resistance is indicative of continual refinement in the pore structure resulting from ongoing cement hydration and pozzolanic reactions, causing a reduction in ionic conduction with time. 


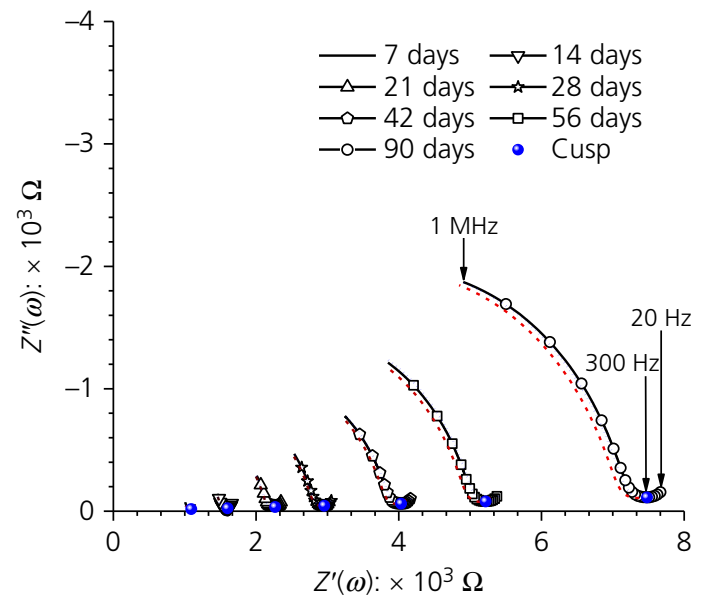

(a)

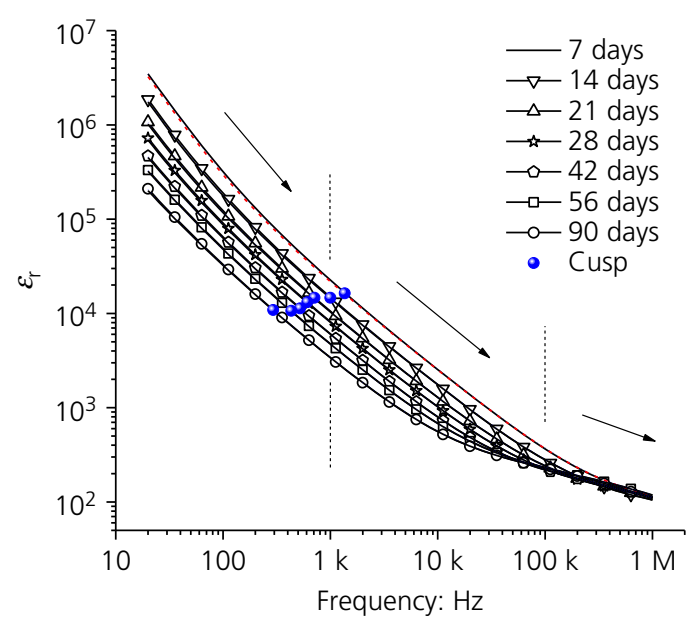

(c)

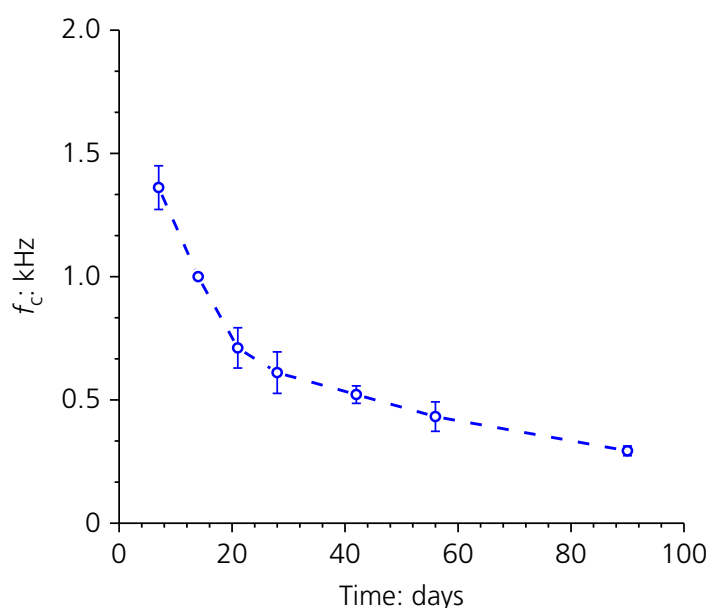

(b)

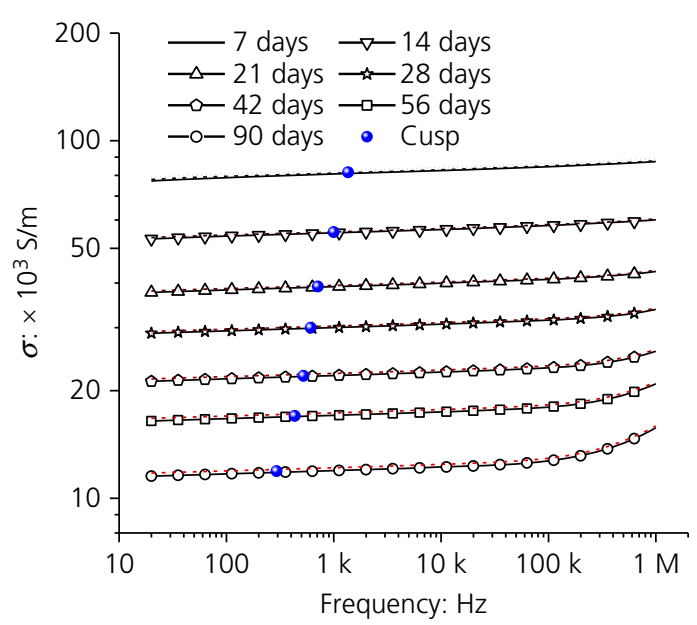

(d)

Figure 4. Influence of curing on the electrical properties of prisms P1-P3 over the initial 90 days of curing: (a) impedance response; (b) variation in cusp-point frequency $f_{c}$; (c) relative permittivity against frequency; (d) conductivity against frequency. The solid markers in (c) and (d) indicate the permittivity/conductivity corresponding to the cusp-point of the impedance response presented in (a)

With reference to Figure 4(a), it is evident that the progressive increase in bulk resistance was accompanied by displacement of the impedance spectrum to the right, implying an increase in the sample impedance over the entire frequency range. It is also interesting to observe that the definition of the bulk arc became more discernible over time when measured within the same frequency range $(20 \mathrm{~Hz}-1 \mathrm{MHz})$. This manifests as a reduction in the cusp-point frequency $\left(f_{\mathrm{c}}\right)$ with increasing curing time across the entire impedance spectrum. For illustrative purposes, Figure 4(b) shows the change in $f_{\mathrm{c}}$ (i.e. the frequency corresponding to the minimum point within the U-shaped valley region) over the 90-day curing period, with the error bars representing \pm one standard deviation (SD). A reduction in $f_{\mathrm{c}}$ was evident over the initial 21 days, followed by a more gradual decrease in frequency over the remainder of the test period, reflecting ongoing hydration and resulting microstructural changes within the composite.
To provide an improved understanding of these mechanisms, the frequency-dependent parameters (relative permittivity $\kappa_{\mathrm{r}}^{\prime}(\omega)$ and conductivity $\left.\sigma(\omega)\right)$ are now presented and discussed.

\section{Relative permittivity and bulk conductivity} (no tensile loading)

In a heterogeneous system such as an ECC, a number of polarisation processes can operate simultaneously within the system within an overlapping frequency range. Each process may relax according to its own time constant, which makes it difficult to determine accurately the contribution of each individual mechanism to the polarisability of the system.

The relative permittivity provides a relative measure of the polarisability of the system and, at any particular frequency of applied electrical field, quantifies the sum of all polarisation mechanisms operating at that frequency. Presenting the 
permittivity in the frequency domain can therefore give a clearer view of the dominant polarisation mechanisms (and the frequency range over which they operate). The relative permittivity $\kappa_{\mathrm{r}}^{\prime}(\omega)$, which was de-embedded from the impedance data of prisms P1-P3 using Equation 3, is presented in the frequency domain in Figure 4(c). It is apparent from this figure that a region of dispersion exists, as evidenced by the progressive reduction in permittivity up to the upper frequency limit. There is also a distinct change in the rate of dispersion across the entire frequency range presented. Consider, for example, the permittivity at 7 days, $\sim 3.4 \times 10^{6}$ at $20 \mathrm{~Hz}$; this decreased by almost two orders of magnitude to $\sim 2.2 \times 10^{4}$ at $1 \mathrm{kHz}$, $\sim 370$ at $100 \mathrm{kHz}$ and $\sim 115$ at $1 \mathrm{MHz}$. Within the frequency range, it is postulated that three dominant mechanisms of polarisation are operative.

(a) Polarisation processes at the electrode/sample interface, commonly referred to as electrode polarisation (Ishai et al., 2013; McCarter et al., 2009, 2015), which can result in anomalously high permittivity values. This is

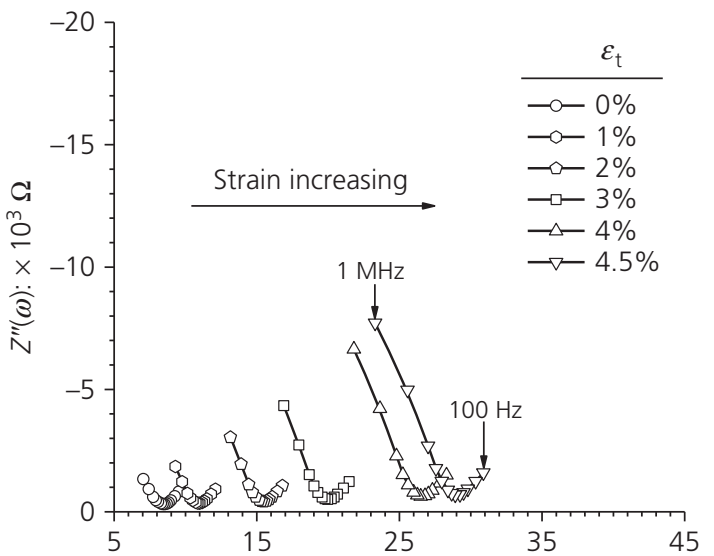

(a)

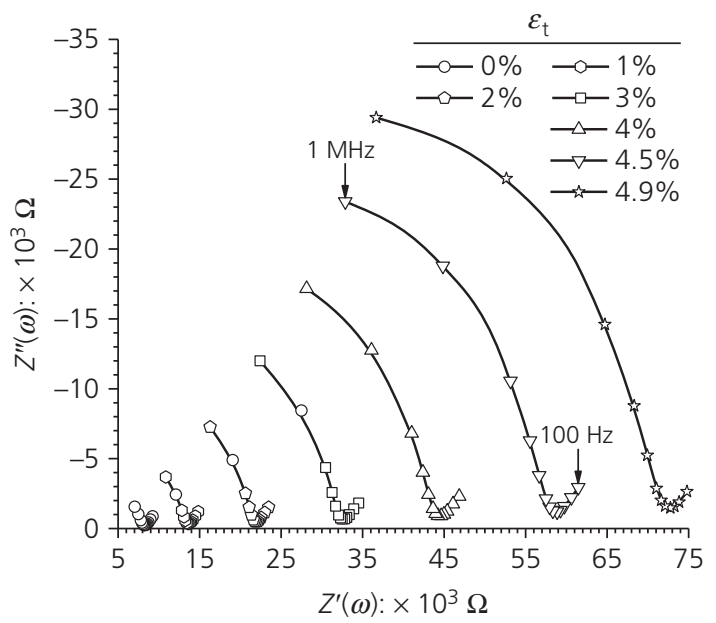

(c) generally a low-frequency mechanism, typically relaxing in the low $\mathrm{kHz}$ range.

(b) Double-layer polarisation due to charges electrostatically held on the surfaces of the cement gel and other particles such as FA and fine sand (McCarter et al., 2002;

Schwan et al., 1962; Schwarz, 1962). This is a low/medium-frequency mechanism and may operate up to the $\sim 100 \mathrm{kHz}$ region.

(c) Interfacial or space charge polarisation resulting from the accumulation of charges at the interface of two dissimilar materials with different relaxation times, also known as Maxwell-Wagner polarisation (Hasted, 1973; Iwamoto, 2012; McCarter et al., 2002; Prodromakis and Papavassiliou, 2009). In a cement-based system including ECCs, this can arise from translating charges that are blocked inside isolated pores and accumulate at pore water/hydrate interfaces. Interfacial polarisation is an intermediate-frequency mechanism, operating typically over high-kilohertz into the megahertz.

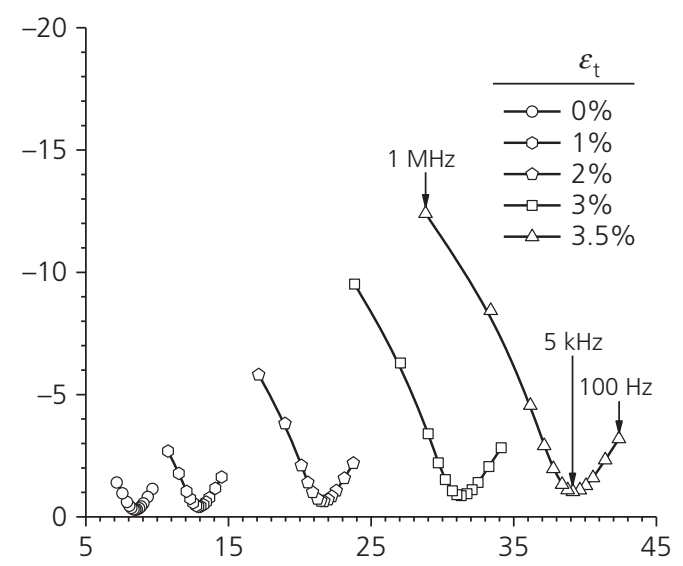

(b)

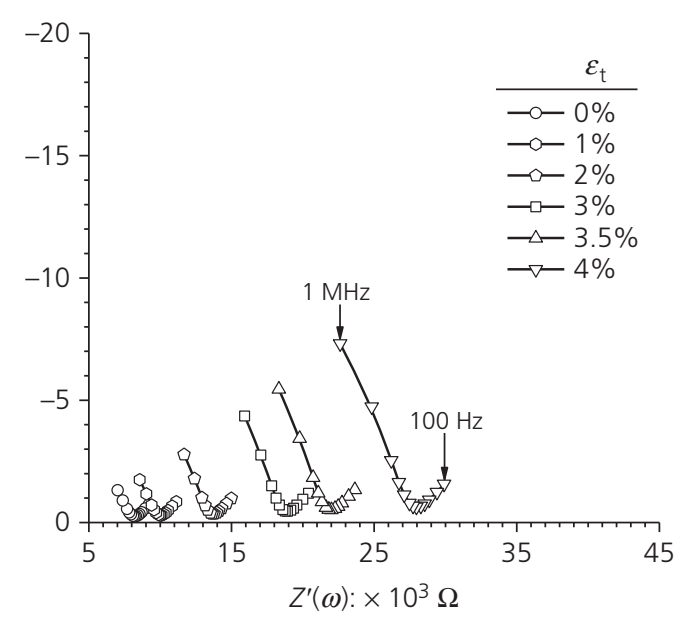

(d)

Figure 5. Variation in impedance response with tensile strain: (a) DB1; (b) DB2; (c) DB3; (d) DB4 
With reference to Figure 4(c), it is proposed that the mechanism responsible for the decrease in permittivity at frequencies $<1 \mathrm{kHz}$ is the relaxation of polarisation processes at the electrode/sample interface, possibly overlapping with relaxation of double-layer process within the composite itself. Within the frequency range $1 \mathrm{kHz}-1 \mathrm{MHz}$, it is proposed that the continuing decrease in permittivity is as a direct result of two superimposed mechanisms: the relaxation of double-layer processes, operating primarily within this frequency range, and the relaxation of interfacial (Maxwell-Wagner) processes, which have a more dominant influence at frequencies $>100 \mathrm{kHz}$.

It is also interesting to note from the results presented in Figure 4(c) that there was a reduction in the magnitude of the dispersion/relaxation with increasing curing time, from $\sim$ five orders of magnitude at 7 days to $\sim$ three orders of magnitude at 90 days. This is attributed, in part, to the reduction in relaxation time discussed above and to the change in the dispersive polarisation processes with time.

To further investigate the dispersive behaviour of the material, Figure 4(d) shows the bulk conductivity in the frequency domain, with the conductivity de-embedded from the impedance measured from prisms P1-P3 using Equation 2. Conductivity gives a measure of both ionic conduction through the movement of ions within the continuous capillary pore network, which is low-frequency feature, and a dispersive conduction contribution resulting from the relaxation of polarisation processes, which is dependent on the frequency of the applied field. It can be inferred from the conductivity plots shown in Figure 4(d) that dispersion resulted in a very gradual

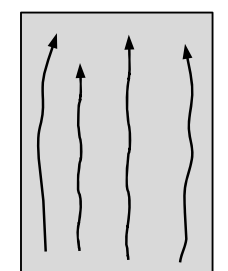

Uncracked matrix $\left(\varepsilon_{\mathrm{t}}=0\right)$

Matrix with partially developed microcracks

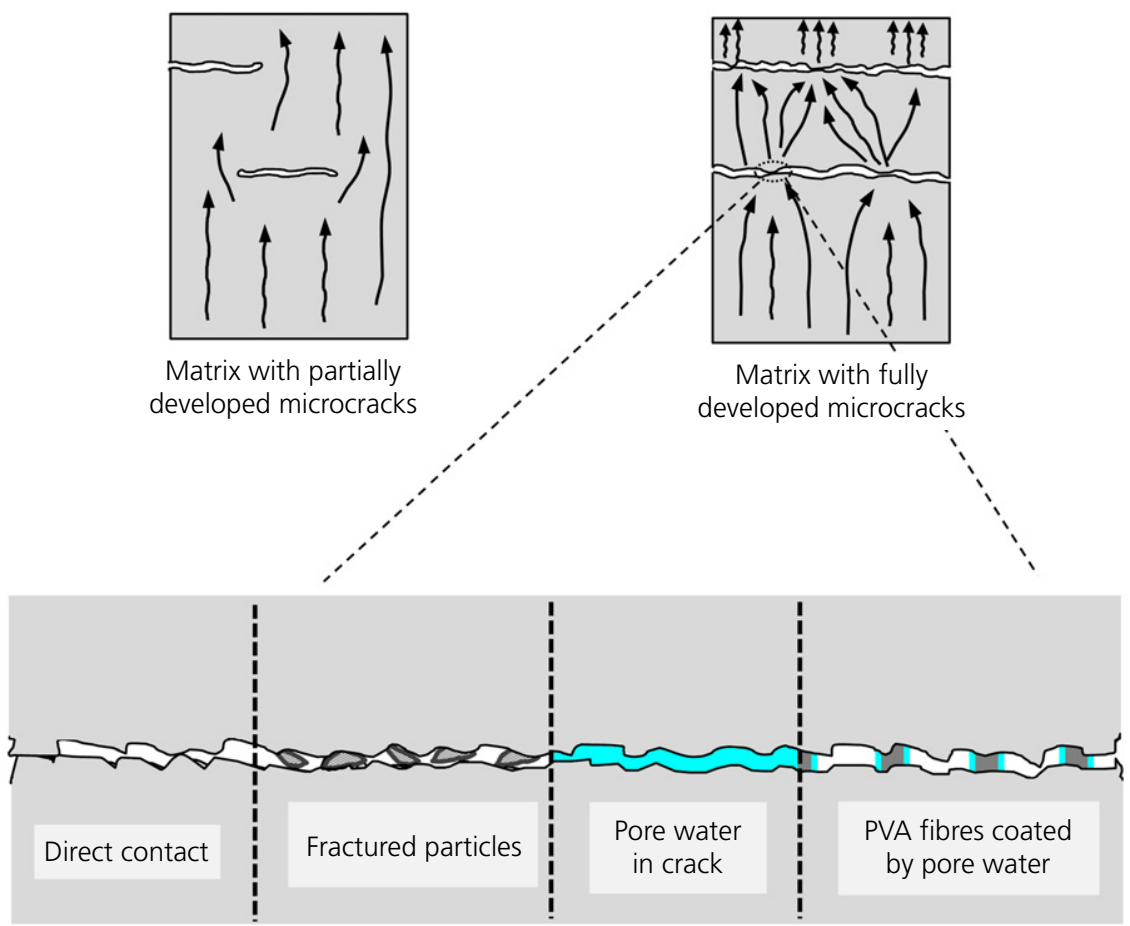

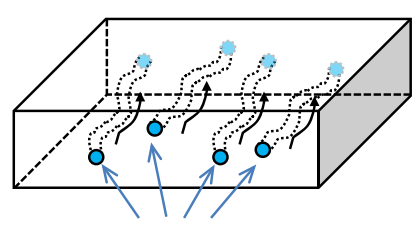

Water-filled capillary pores

(a)

(b)

Figure 6. Schematic illustration of possible conduction pathways in (a) uncracked and (b) cracked ECC matrix showing possible bridging pathways 
increase in conductivity across the entire frequency range, indicating the existence of the relaxation of polarisation processes over the entire range. This would indicate that the polarisation mechanisms operate at an overlapping frequency range, resulting in a spread of the relaxation time. Owing to the gradual increase, it would be difficult to separate the underlying mechanisms from this presentation formalism, with the exception of the conductivity at 56 and 90 days of curing in which a more noticeable increase in conductivity was evident at frequencies greater than $\sim 100 \mathrm{kHz}$. This is attributed primarily to the relaxation of interfacial processes, as discussed above.

\section{Piezo-impedance study}

\section{Complex impedance response under tensile loading}

The complex impedance plots of specimens DB1 to DB4 during tensile loading conducted on the 28th day of curing are presented in Figures 5(a)-5(d). Owing to the number of data points in each curve (i.e. measurements at 13 spot frequencies), the data markers were connected with B-splines and, for reasons of clarity, only the responses at $1 \%$ strain increments are presented. At any stage of loading, the cracked ECC displayed a classic response, comprising an arc forming the left-hand side of the plot and a spur forming the right-hand side, which is not dissimilar to the response observed in the hydration study (see Figure 4(a)). It is apparent from Figures 5(a)-5(d) that tensile straining resulted in the entire response being gradually displaced to the right, indicating an overall increase in impedance with increasing strain. With reference to Figures 6, this gradual increase is as a direct result of the successive formation and widening of multiple microcracks (Saraireh et al., 2017; Wansom and Kanokkanchana, 2017), which have the effect of altering the conduction pathway within the composite, from a relatively straight pathway (Figure 6(a)) to a more tortuous one (Figure 6(b)). Accordingly, an increase in tensile strain has the effect of reducing the continuity and increasing the

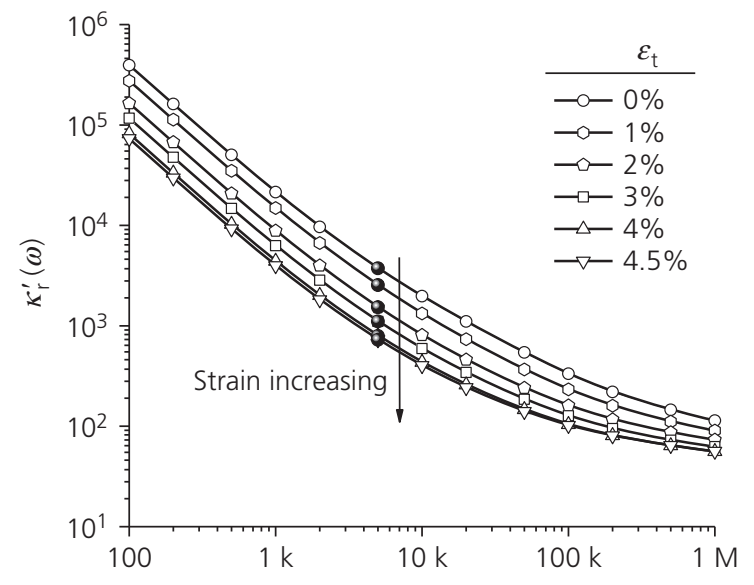

(a)

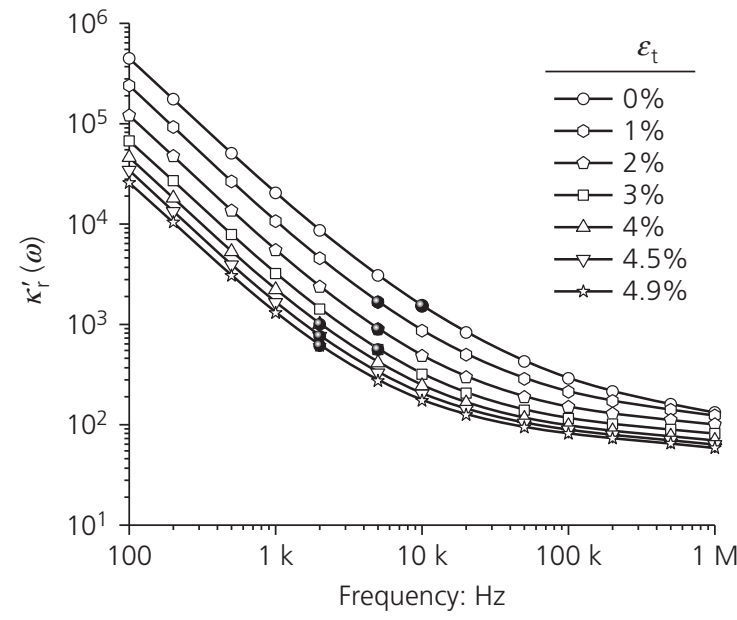

(c)

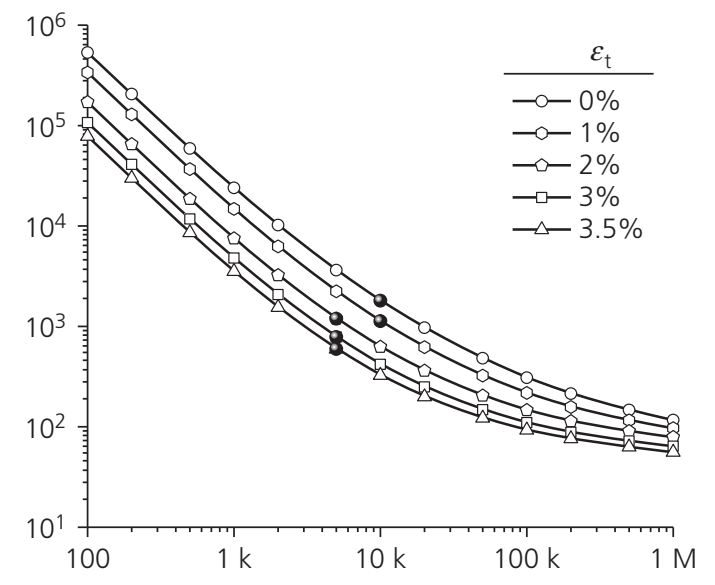

(b)

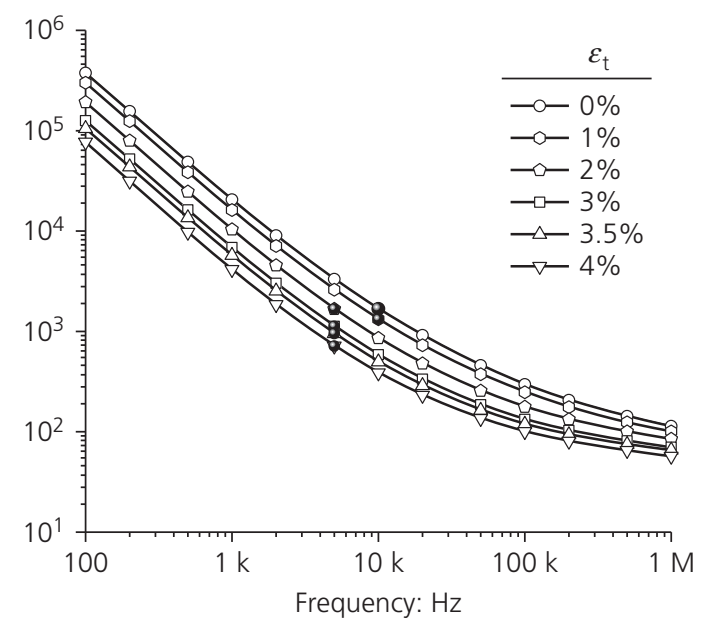

(d)

Figure 7. Relative permittivity against frequency at selected strain levels: (a) DB1; (b) DB2; (c) DB3; (d) DB4. The cusp-point frequency is shown as a solid marker 
circuitous path length, hence increasing the overall impedance of the ECC. Conduction will occur through several possible mechanisms across the microcrack as depicted in Figure 6(b); at this stage, however, it is difficult to delineate the contribution from each pathway.

Another interesting feature that is apparent from Figures 5(a)-5(d) relates to the definition of the high-frequency arc associated with the bulk response of the material including microcracks. The arc became more pronounced with an increase in strain, indicating a shift in time constant to the frequency range under investigation, as in the hydration study.

\section{Relative permittivity and bulk conductivity} under tensile loading

Figure 7 shows the relative permittivity of specimens DB1DB4, computed using Equation 3, plotted in the frequency domain with varying tensile strains and marked at every $1 \%$ increment of strain. In general terms, the trend in the relative permittivity plots is, in many respects, similar to the respective specimens in the hydration study (see Figure 4(c)), characterised by a reduction in relative permittivity with increasing frequency across the entire frequency range. As before, this is due to the relaxation of superimposed polarisation mechanisms operating within the composite and the shift in time constant with increasing strain, which has the effect of shifting the relative permittivity curve to the left along the $Z^{\prime}$ axis toward the origin.

It is interesting to note that while the relative permittivity plots presented in Figure 4(c) all merge at frequencies greater than $\sim 200 \mathrm{kHz}$, this was not the case for the plots presented in Figure 7, which display a progressive downward displacement with increasing strain across the entire frequency range, including high frequencies (i.e. $>200 \mathrm{kHz}$ ). This can be associated
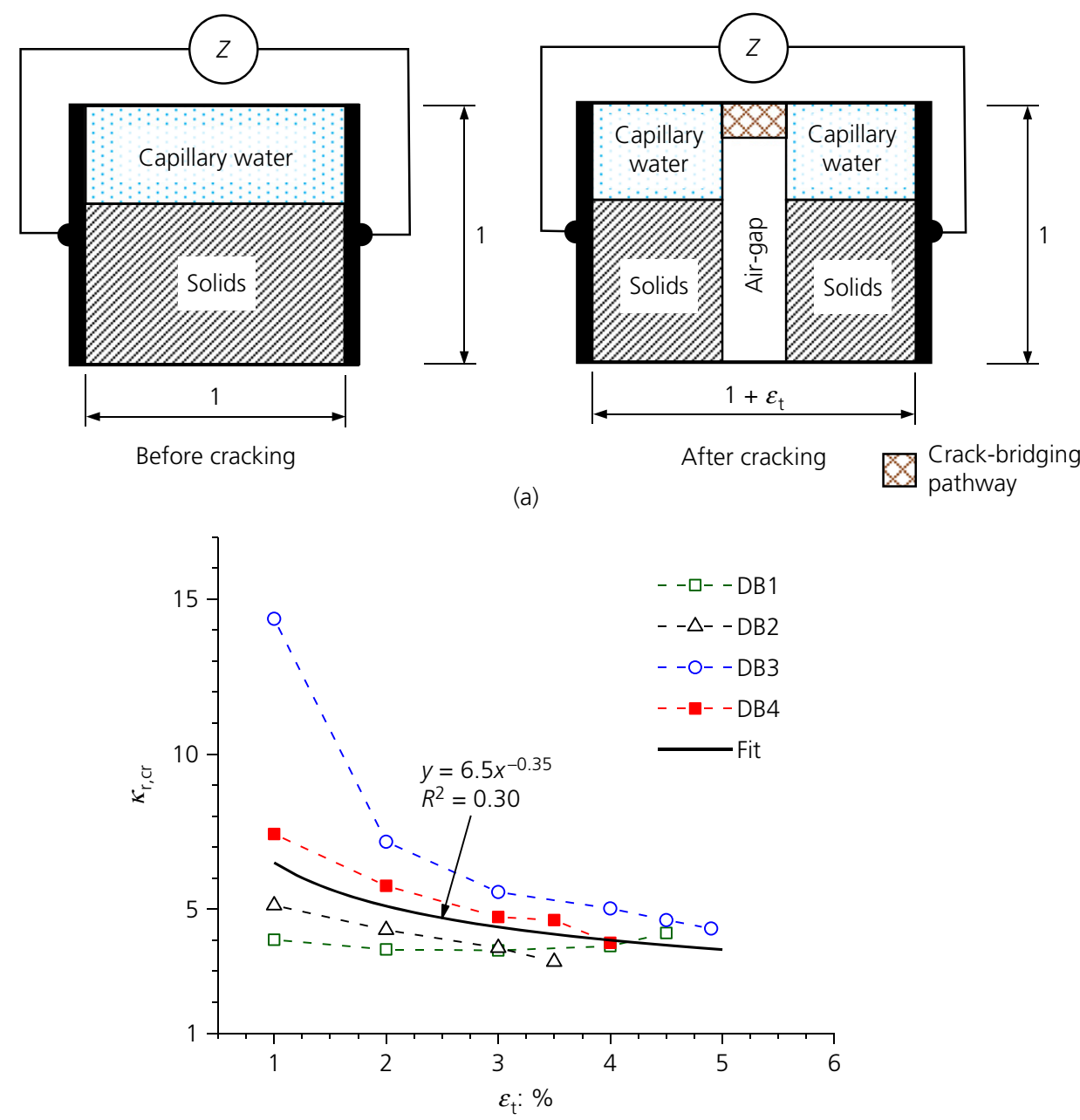

(b)

Figure 8. (a) Idealised representation of ECC before and after cracking; (b) Variation in relative permittivity of microcracks assuming a series mixing law (Equation 6) 
with the progressive formation microcracks within the ECC matrix; as the relative permittivity of the air gap between two opposite cracked surfaces is $\sim 1$, multiple crack formation would have the effect of decreasing the overall polarisability of the system. To understand this aspect, consider the idealised system presented in Figure 8(a), composed of the saturated ECC matrix and a crack comprising an air gap and a crackbridging pathway. The bridging pathway would represent all the possible pathways presented in Figure 6(b), so could be regarded as a smeared contribution. Given that the microcracks are, in essence, connected in series with the bulk ECC matrix, the permittivity of the microcracks could be estimated by the mathematical mixing law (Reynolds and Hough, 1957)

6. $\frac{\phi_{\mathrm{r}, \mathrm{t}}}{\kappa_{\mathrm{r}, \mathrm{t}}}=\frac{\phi_{\mathrm{cr}}}{\kappa_{\mathrm{cr}}}+\frac{\phi_{\mathrm{r}, \mathrm{i}}}{\kappa_{\mathrm{r}, \mathrm{i}}}$ where $\kappa_{\mathrm{r}, \mathrm{t}}$ is the bulk relative permittivity of the composite at strain $\varepsilon_{\mathrm{t}}$ after the start of the test, $\kappa_{\mathrm{cr}}$ is the average relative permittivity of the microcracks and $\kappa_{\mathrm{r}, \mathrm{i}}$ is the bulk relative permittivity of the composite at the start of the test (i.e. $\varepsilon_{\mathrm{t}}=0$ ). Both $\kappa_{\mathrm{r}, \mathrm{t}}$ and $\kappa_{\mathrm{r}, \mathrm{i}}$ were evaluated at the upper frequency limit which, in the present study, was $1 \mathrm{MHz}$. With reference to the system shown in Figure 8(a), the total volume at strain $\varepsilon_{\mathrm{t}}$ after the start of the test is given by $\phi_{\mathrm{r}, \mathrm{t}}=\phi_{\mathrm{r}, \mathrm{i}}+\phi_{\mathrm{cr}}$, where $\phi_{\mathrm{r}, \mathrm{i}}$ is the initial volume at the start of the test and $\phi_{\mathrm{cr}}$ is the volume fraction of microcracks at strain $\varepsilon_{\mathrm{t}}$.

Figure 8 (b) shows the average relative permittivity of the microcracks computed using Equation 6 at discrete tensile strain levels. The results show that the value of the apparent permittivity of the microcracks was consistently higher than that of air $(\approx 1)$, indicating the presence of other materials within the space between two microcrack surfaces. The plots also display the variations in calculated permittivity values,

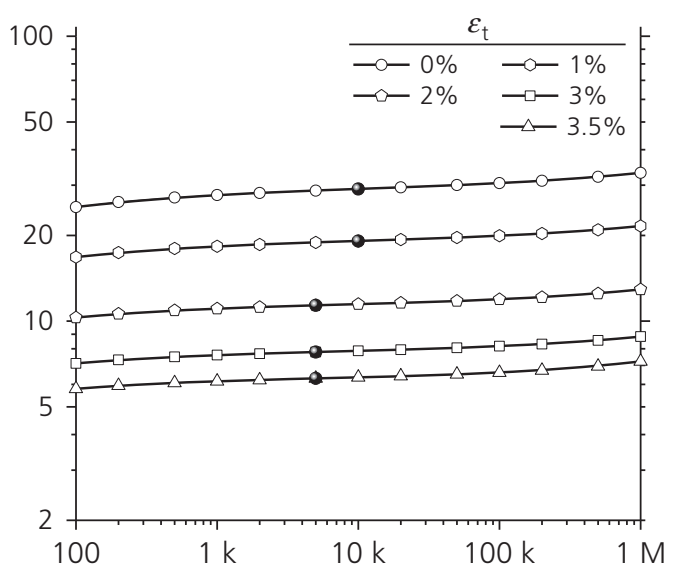

(b)

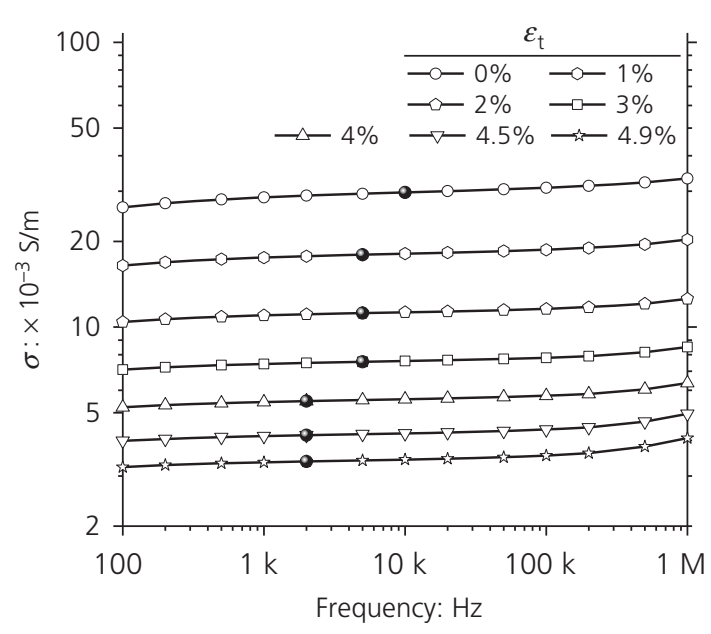

(c)

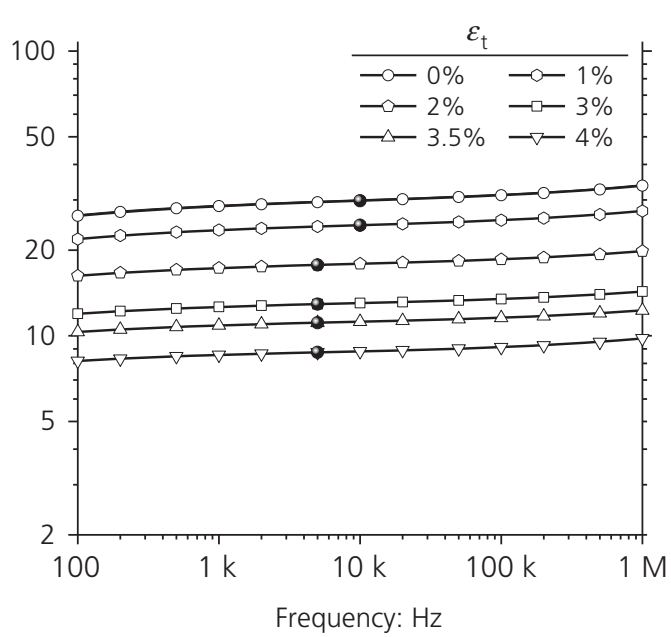

(d)

Figure 9. Conductivity-frequency response under tensile load: (a) DB1; (b) DB2; (c) DB3; (d) DB4. The cusp-point frequency is shown as a solid marker 
with a general decreasing trend with increasing tensile strain up to $\sim 4 \%$, where the permittivity plateaus at $\sim 4$. The best-fit power equation was added to provide an alternative means of predicting the tensile strain in a fully saturated system from permittivity measurements. The variation in permittivity would indicate the spatial distribution in the number of physical pathways across the crack (see Figure 6(b)), while the reduction in permittivity with increasing strain is indicative of their temporal change during the loading process.

To highlight further the influence of crack formation on the bulk electrical properties of cracked the ECC, the bulk conductivity of specimens DB1-DB4 at varying strains is presented in the frequency domain in Figures 9(a)-9(d). As before, owing to the relaxation of the polarisation mechanisms operating within the ECC matrix, the conductivity gradually increased with frequency across the entire frequency range. Tensile straining was shown to result in a downward, parallel displacement of the bulk conductivity curves, resembling the trend shown in Figure 4(d). This is as a direct result of the formation of microcracks with increasing load rather than pore refinement due to hydration, as the duration of the tensile test was short (less than $10 \mathrm{~min}$ ). As the tensile strain increased, microcracks progressively formed within the ECC matrix, causing a reduction in conductivity with increasing strain.

To highlight the sensing capability of the composite, the conductivity of specimen DB2 is, for illustrative purposes, plotted against the tensile strain in Figure 10(a) together with the corresponding stress-strain relation. The conductivity is presented at selected spot frequencies (i.e. $100 \mathrm{~Hz}, 500 \mathrm{~Hz}$, $5 \mathrm{kHz}, 100 \mathrm{kHz}, 500 \mathrm{kHz}$ and $1 \mathrm{MHz}$ ) and the response near to the cusp-point frequency $\left(f_{\mathrm{c}}=5 \mathrm{kHz}\right)$ is highlighted with data markers. In this curve, only every tenth data marker is highlighted, for reasons of clarity. This figure clearly shows the dependence of bulk conductivity on both the tensile strain and

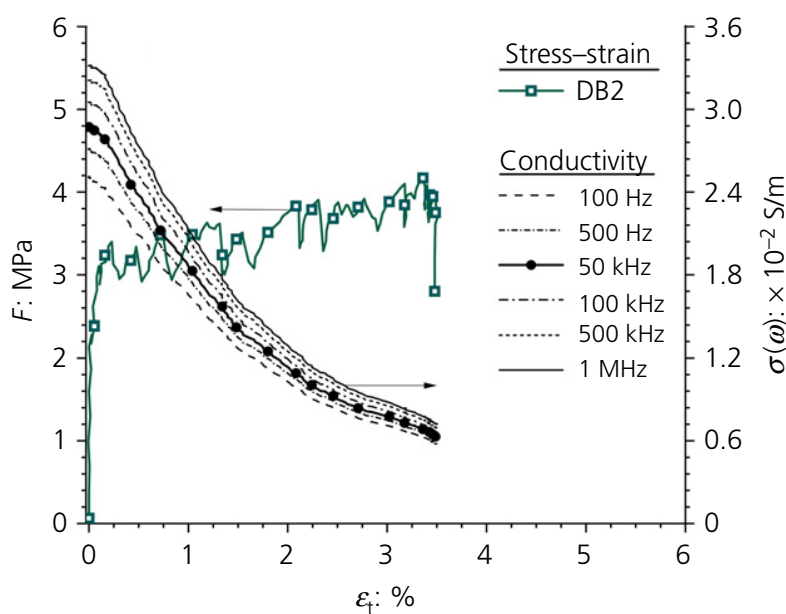

(a)

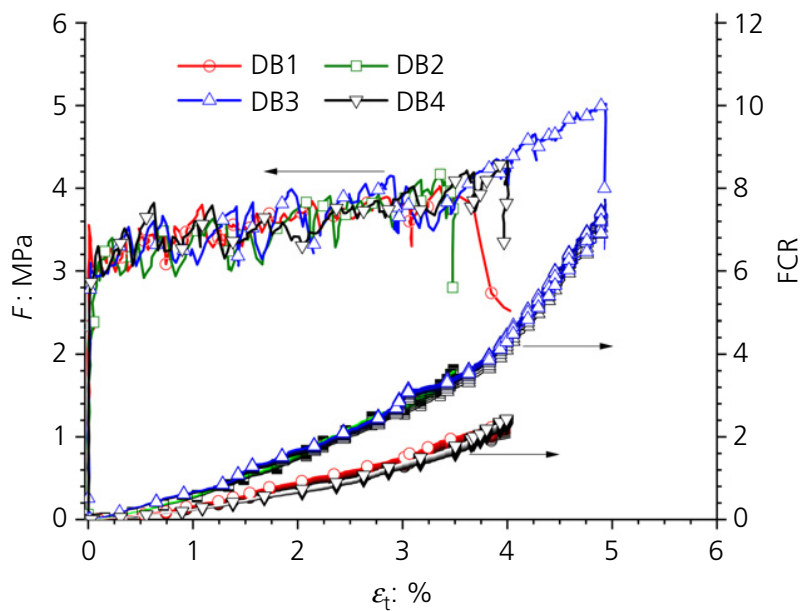

(b)

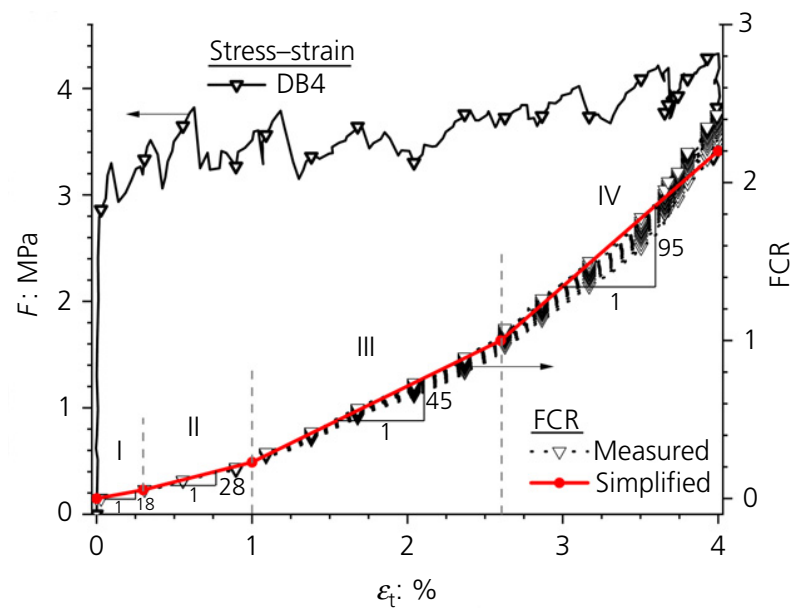

(c)

Figure 10. (a) Variation in bulk conductivity of specimen DB2 under varying tensile strains; (b) FCR for specimens DB1-DB4 under varying tensile strains; (c) Representation of FCR of specimen DB4 into contiguous linear segments. All curves are plotted alongside the stressstrain responses 
the test frequency. As the strain increases to $\sim 0.15 \%$, a reduction in conductivity is evident as microcracks began to develop within the ECC matrix; the dominant conduction path at this stage would be by way of the uncracked portion. This is then followed by a rapid reduction in conductivity with increasing strain, resulting in an approximately fivefold decrease in value. To investigate the sensitivity of the composite to mechanical strain, the bulk conductivity $\sigma(\omega)$ was converted to its reciprocal (bulk resistivity $\rho(\omega)$ ) and then used to calculate the fractional change in resistivity (FCR), which is defined as (Chia and Huang, 2017; Han et al., 2011; Ozbulut et al., 2018; Ranade et al., 2014; Wen and Chung, 2003; Yang et al., 2018; Yoo et al., 2019)

7. $\mathrm{FCR}=\frac{\rho_{\mathrm{t}}-\rho_{\mathrm{i}}}{\rho_{\mathrm{i}}}$ where $\rho_{\mathrm{t}}$ is the bulk resistivity at strain $\varepsilon_{\mathrm{t}}$ after the start of the test and $\rho_{\mathrm{i}}$ is the initial bulk resistivity (i.e. at zero strain).

Figure 10(b) shows the FCR values for the four dogboneshaped specimens over the entire frequency range plotted against the fractional change in dimension (or strain), together with the stress-strain response measured from individual dogbone-shaped specimens. As before, for reasons of clarity, only the tenth data markers are highlighted in all the curves and the FCR is presented to highlight its sensitivity to frequency. It is interesting to note from the figure that, by presenting the resistivity data in a dimensionless format (i.e. FCR against the fractional change in dimension), this virtually removes the dependence of the FCR on frequency and the resistivity curves all collapse into a unique curve. It is evident that all the specimens exhibited a quasi-linear increase in FCR with strain, with a notable increase in slope with
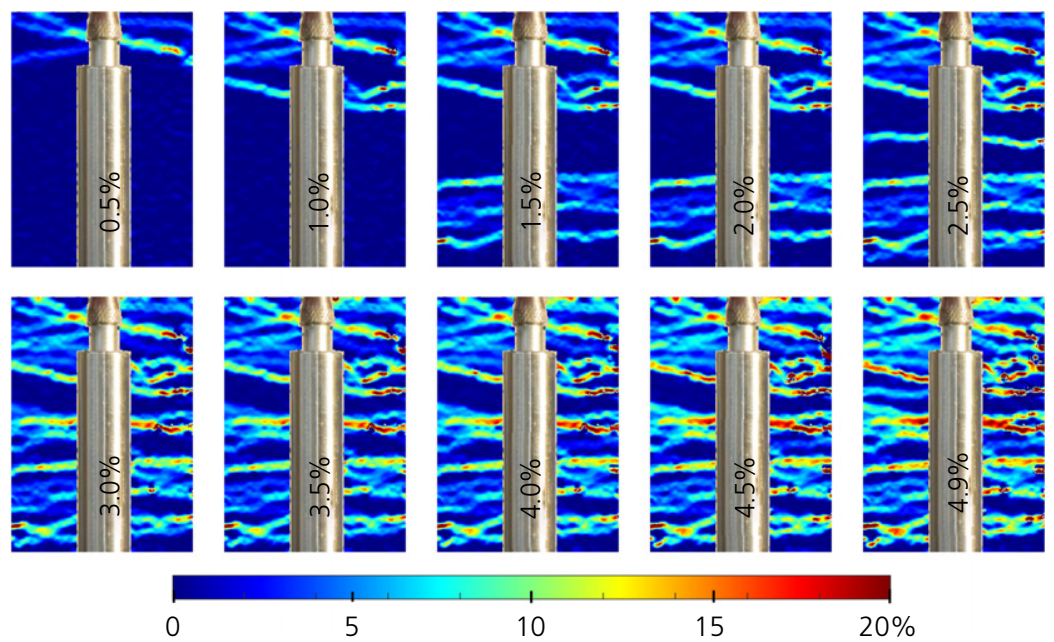

(a)

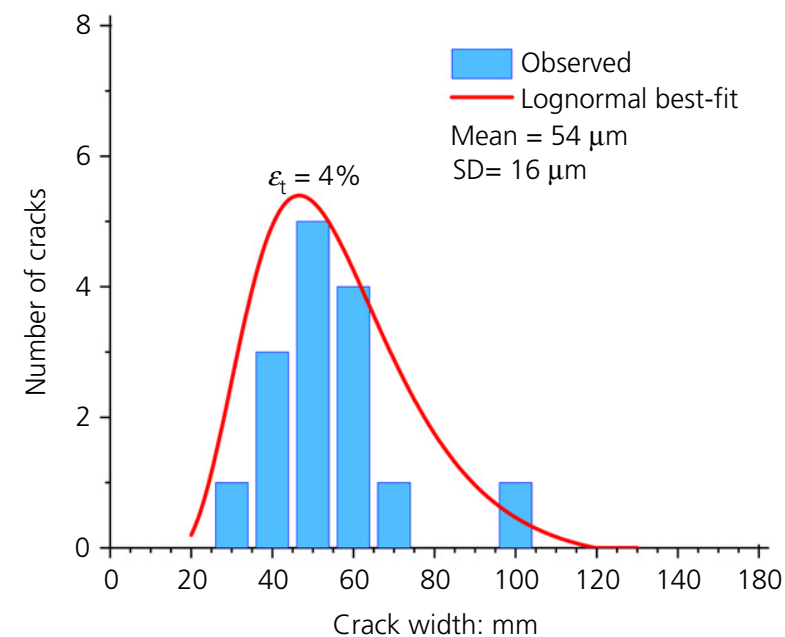

(b)

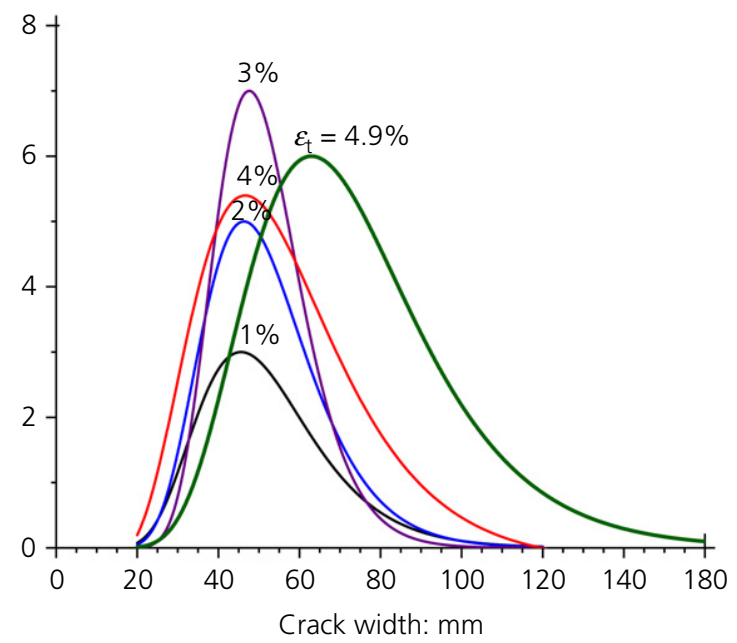

(c)

Figure 11. (a) Progressive development of longitudinal strains on the front face of specimen DB3; (b) Observed and fitted crack width distribution at $4 \%$ strain from visual observations; (c) Fitted crack width distributions at varying strain levels 
increasing strain. The slope of specimen DB3 increased more appreciably at strain levels greater than $\sim 3 \%$, which coincides with the increase in the post-cracking stiffness shown in the figure, reflecting the slip hardening behaviour resulting from abrasion damage on the fibre surfaces as fibres are pulled out from the ECC matrix (Redon et al., 2001). This figure also indicates that the FCRs of specimens DB2 and DB3 were very similar and consistently greater than the FCRs of the other two specimens, which also showed similar responses. The FCR at $4 \%$ strain was in the range $2.4-4.2$; this is comparable to the values reported by Ranade et al. (2014) for a high-volume FA ECC mix and lower than those for the moderate-volume FA ECC mix.

By plotting the FCR against strain as in Figure 10(b), distinct regions can be delineated, as shown in Figure 10(c): region I (up to $\sim 0.3 \%$ strain), region II $(0.3-1 \%$ strain), region III
(1-3\% strain) and region IV (>3\% strain, with the slope values also provided in the figure. Considering the variations in FCR during the strain hardening discussed above, it is interesting to note that this is not evident in the stress-strain responses of specimens DB1-DB4 presented in Figure 10(b), with all specimens displaying a comparable overall stiffness during strain hardening. As the electrical response of the specimens was affected by the presence of microcracks, the apparent difference may thus originate from the distribution of the microcracks during loading. Attention thus turned to the number and width of individual microcracks during loading.

\section{Crack mapping during tensile loading}

To corroborate the electrical measurements regarding microcracking, Figures 11(a) and 12(a) show representative longitudinal strain maps for specimens DB3 and DB4, respectively, obtained using the DIC technique at every $0.5 \%$ strain
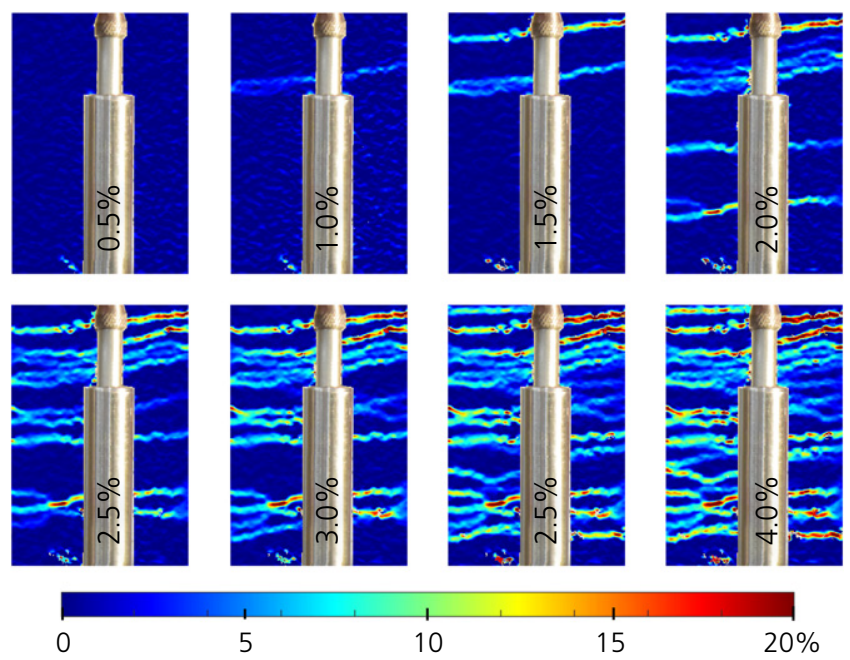

(a)

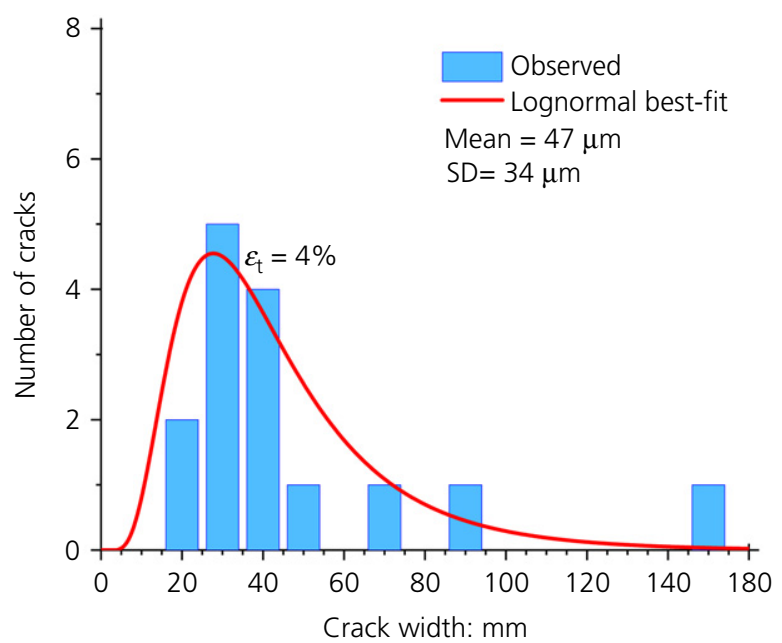

(b)

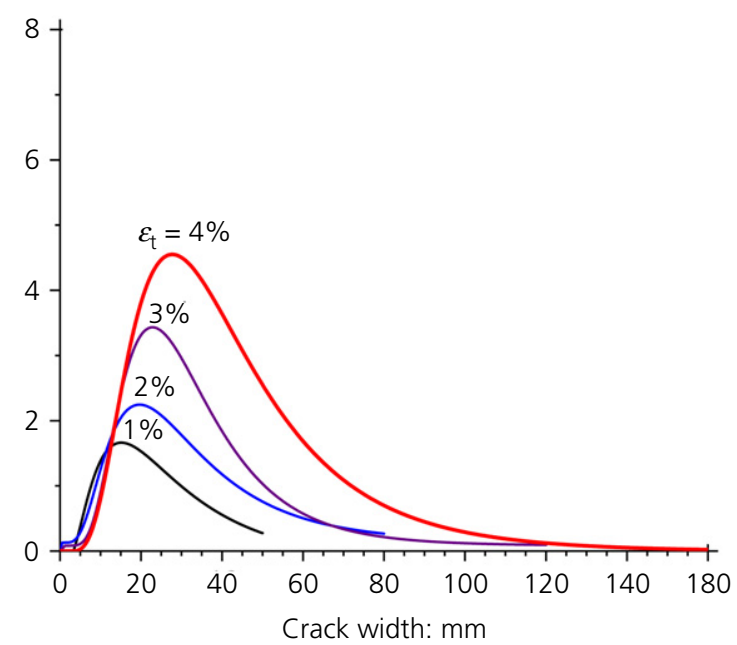

(c)

Figure 12. (a) Progressive development of longitudinal strains on the front face of specimen DB4; (b) Observed and fitted crack width distribution at $4 \%$ strain from visual observations; (c) Fitted crack width distributions at varying strain levels 
increment. The crack width distributions measured at $4 \%$ strain and the corresponding best-fit lognormal distribution curves for specimens DB3 and DB4 are plotted in Figures 11(b) and 12(b), respectively, with the best-fit lognormal distribution curves at $1 \%$ strain increment presented in Figures 11(c) and 12(c) to aid data interpretation. It is apparent from the crack width distribution of specimen DB3 (Figure 11(c)) that there was a significant increase in the number of cracks at $3 \%$ strain, whereas the average crack width over this strain range was relatively constant. The combined effect of this caused the displacement of the crack width distribution upwards. Thereafter, there was a notable increase in the average crack width from $\sim 47 \mu \mathrm{m}$ at $3 \%$ strain to $65 \mu \mathrm{m}$ at $4.9 \%$ strain, thereby causing the distribution curve shown in Figure 11(c) to displace to the right. This trend agrees well with the strain maps shown in Figure 11(a), which display an increasing number of near-parallel bands of localised strain with a relatively constant colour range over the initial 3\% strain, followed by a similar pattern of strain maps but with a notable increase in value. It could be inferred from the evolution of the crack pattern obtained that the increase in the FCR for specimen DB3 over the initial 3\% strain is attributed primarily to microcrack formation whereas the increase in both values thereafter is due to the widening of existing microcracks.

With reference to the evolution of crack pattern of specimen DB4 (Figures 12(a) and 12(c)), it is evident that microcrack formation occurred constantly throughout the loading, from two fully-developed microcracks at $1 \%$ strain to 15 cracks at $4 \%$ strain, which was also accompanied by a notable increase in the average crack width. This would indicate that the predominant mechanism responsible for the increase in the FCR presented in Figure 10(b) was due to progressive crack formation, with a significant contribution of crack width increase at strain levels $>3 \%$. It is interesting to note from both specimens that, although they had more or less the same number of cracks $(\sim 15)$ with an average crack width of $\sim 50 \mu \mathrm{m}$ at $4 \%$ strain, the two specimens attained different FCR values, with those of specimen DB3 approximately twice those of specimen DB4. This would suggest the need for using the actual crack width distribution to allow for an accurate calculation of FCR; work is continuing on this aspect.

\section{Conclusions}

A multiple testing methodology of electrical impedance measurements, mechanical testing and detailed image analysis was employed to investigate the piezo-impedance properties of an ECC under direct tension, with the impedance measurements also used to provide complementary information on the influence of ongoing hydration. The following conclusions can be drawn from the results presented.

(a) A distinct impedance response was observed at all stages during the hydration process. Increasing hydration was found to result in an overall increase in impedance and a better definition of the high-frequency arc, which reflects the development of pore structure over time. A progressive increase in bulk resistance was evident during the entire curing period, reflecting ongoing hydration and pozzolanic reactions.

(b) Dispersion in polarisation was shown to result in a reduction in relative permittivity with increasing frequency and a corresponding increase in conductivity. Ongoing hydration and pozzolanic reactions were found to have a negligible influence on the relative permittivity at the upper frequency limit (i.e. $1 \mathrm{MHz}$ ).

(c) Multiple microcrack formation increased the sample impedance markedly and resulted in a progressive displacement and enlargement in the radius of the bulk arc when presented in the Nyquist format.

(d) The relative permittivity at the high-frequency end ( $1 \mathrm{MHz}$ ) was found to be sensitive to tensile straining, while virtually insensitive to ongoing hydration. This parameter could therefore be exploited as a means of distinguishing changes in electrical properties due to ongoing hydration and changes in electrical properties due to damage within the composite, when the matrix remains in a fully saturated condition.

(e) The composite sensitivity to strain was affected by the distribution of microcracks. Larger FCR values were obtained from specimens with greater crack widths.

\section{Acknowledgements}

The authors wish to acknowledge the financial support of the UK Engineering and Physical Sciences Research Council (grant EP/N028597/1), Kuraray Japan and Kuraray GmbH for the supply of PVA fibres and BASF UK for the supply of HRWR. DS also acknowledges the financial support provided by Heriot-Watt University. Thanks also go to Dr Asdam Tambusay for assistance in part of the experimental work and DIC analysis.

\section{REFERENCES}

Abé M and Fujino Y (2017) Monitoring of long-span bridges in Japan. Proceedings of the Institution of Civil Engineers - Civil Engineering 170(3): 135-144, https://doi.org/10.1680/jcien.16.00002.

Agdas D, Rice JA, Martinez JR and Lasa IR (2015) Comparison of visual inspection and structural-health monitoring as bridge condition assessment methods. Journal of Performance of Constructed Facilities ASCE 30(3): 04015049.

Azhari F and Banthia N (2012) Cement-based sensors for piezoresistive sensing. Cement \& Concrete Composites 34(7): 866-873.

Blaber J, Adair B and Antoniou A (2015) Ncorr: open-source 2D digital image correlation mat-lab software. Experimental Mechanics 55(6): 1105-1122.

BSI (2011) BS EN 197-1:2011. Cement. Composition, specifications and conformity criteria for common cements. BSI, London, UK.

Chen Y, Yu J and Leung CK (2018) Use of high strength strain-hardening cementitious composites for flexural repair of concrete structures with significant steel corrosion. Construction and Building Materials 167: 325-337. 
Chia L and Huang Y (2017) Dispersion effectiveness of carbon nanotubes in smart cementitious materials. Advances in Cement Research 29(6): 246-257, https://doi.org/10.1680/jadcr.17.00013.

Choi S, Park S, Bolton R, Stubbs N and Sikorsky C (2004) Periodic monitoring of physical property changes in a concrete box-girder bridge. Journal of Sound and Vibration 278(1-2): 365-381

Frangopol DM, Dong Y and Sabatino S (2017) Bridge life-cycle performance and cost: Analysis, prediction, optimisation and decision-making. Structure and Infrastructure Engineering 13(10): 1239-1257.

Frank TE, Lepech MD and Billington SL (2018) Experimental testing of reinforced ECC beams subjected to various cyclic deformation histories. Journal of Structural Engineering ASCE 144(6): 04018052.

Han B, Zhang K, Yu X, Kwon E and Ou J (2011) Nickel particle-based self-sensing pavement for vehicle detection. Measurement 44(9): 1645-1650.

Hasted JB (1973) Aqueous Dielectrics. Chapman \& Hall, London, UK. HE (Highways England) (2017) DMRB Volume 3, Section 1, Part 4, BD 63/17 Highway Structures: Inspection and Maintenance. Inspection. Inspection of Highway Structures. HE, London, UK.

Hedegaard BD, French CEW and Shield CK (2017) Time-dependent monitoring and modeling of I-35W St. Anthony falls bridge. I: Analysis of monitoring data. Journal of Bridge Engineering ASCE 22(7): 04017025 .

Hou TC (2008) Wireless and Electromechanical Approaches for Strain Sensing and Crack Detection in Fiber Reinforced Cementitious Materials. PhD thesis, University of Michigan, Ann Arbor, MI, USA.

Hou TC and Lynch JP (2005) Conductivity-based strain monitoring and damage characterization of fiber reinforced cementitious structural components. In Proceedings of SPIE 5765, Smart Structures and Materials 2005: Sensors and Smart Structures Technologies for Civil, Mechanical, and Aerospace Systems (Tomizuka M (ed.)). SPIE, Bellingham, WA, USA, pp. 419-430.

Ishai PB, Talary MS, Caduff A, Levy E and Feldman Y (2013) Electrode polarization in dielectric measurements: a review. Measurement Science and Technology 24(10): 102001.

Iwamoto M (2012) Maxwell-Wagner effect. In Encyclopedia of Nanotechnology (Bhushan B (ed.)). Springer, Dordrecht, the Netherlands, pp. 1276-1285

JSCE (Japan Society of Civil Engineers) (2008) Recommendations for Design and Construction of High Performance Fiber Reinforced Cement Composites with Multiple Fine Cracks (HPFRCC). JSCE, Tokyo, Japan.

Kim J, McCarter WJ, Suryanto B et al. (2016) Chloride ingress into marine exposed concrete: a comparison of empirical-and physically-based models. Cement \& Concrete Composites 72: $133-145$

Kim J, McCarter WJ and Suryanto B (2018) Performance assessment of reinforced concrete after long-term exposure to a marine environment. Construction and Building Materials 192: 569-583.

LabView (2017) See http://www.ni.com/download/labview-developmentsystem-2017/6698/en/ (accessed 01/01/2018).

Lee SW, Tan KH and Yang EH (2018) Seismic behaviour of interior reinforced-concrete beam-column sub-assemblages with engineered cementitious composites. Magazine of Concrete Research 70(24): 1280-1296, https://doi.org/10.1680/jmacr.17. 00359.

Li VC (2008) Engineered cementitious composite (ECC): Material, structural, and durability performance. In Concrete Construction Engineering Handbook (Nawy EG (ed.)). CRC Press, Boca Raton, USA, FL, pp. 24.1-24.46.

Li Z, Leung C and Xi Y (2009) Structural Renovation in Concrete. Taylor \& Francis, London, UK.
Lin VWJ, Li M, Lynch JP and Li VC (2011) Mechanical and electrica characterization of self-sensing carbon black ECC. In Proceedings of SPIE 7983, Nondestructive Characterization for Composite Materials, Aerospace Engineering, Civil Infrastructure, and Homeland Security 2011 (Wu HF (ed.)). SPIE, Bellingham, WA, USA, paper 798316

Lynch JP, Farrar CR and Michaels JE (2017) Structural health monitoring: technological advances to practical implementations (scanning the issue). Proceedings of the IEEE 104(8): 1508-1512.

Ma H, Herbert E, Ohno M and Li VC (2019) Scale-linking model of self-healing and stiffness recovery in engineered cementitious composites (ECC). Cement \& Concrete Composites 95: 1-9.

McCarter WJ and Brousseau R (1990) The AC response of hardened cement paste. Cement and Concrete Research 20(6): 891-900.

McCarter WJ, Garvin S and Bouzid N (1988) Impedance measurements on cement paste. Journal of Materials Science Letters 7(10): 1056-1057.

McCarter WJ, Starrs G and Chrisp TM (2002) Electrical monitoring methods in cement science. In Structure and Performance of Cements (Bensted J and Barnes P (eds)) Taylor \& Francis, London, UK, pp. 442-456.

McCarter WJ, Starrs G and Chrisp TM (2004) The complex impedance response of fly-ash cements revisited. Cement and Concrete Research 34(10): 1837-1843.

McCarter WJ, Starrs G, Kandasami S, Jones R and Chrisp M (2009) Electrode configurations for resistivity measurements on concrete. ACI Materials Journal 106(3): 258-264

McCarter WJ, Chrisp TM, Starrs G et al. (2012) Developments in performance monitoring of concrete exposed to extreme environments. Journal of Infrastructure Systems ASCE 18(3): $167-175$.

McCarter WJ, Taha HM, Suryanto B and Starrs G (2015) Two-point concrete resistivity measurements: interfacial phenomena at the electrode-concrete contact zone. Measurement Science and Technology 26(8): 085007

McCarter WJ, Suryanto B, Taha HM, Nanukuttan S and Basheer PAM (2017) A testing methodology for performance-based specification. Journal of Structural Integrity and Maintenance 2(2): 78-88.

Ncoor (2018) See http://www.ncorr.com/ (accessed 01/01/2018).

Omar T and Nehdi ML (2018) Condition assessment of reinforced concrete bridges: current practice and research challenges. Infrastructure 3(3): 36.

Ozbulut OE, Jiang Z and Harris DK (2018) Exploring scalable fabrication of self-sensing cementitious composites with graphene nanoplatelets. Smart Materials and Structures 27(11): 115029.

Pines D and Aktan AE (2002) Status of structural health monitoring of long-span bridges in the United States. Progress in Structural Engineering and Materials 4(4): 372-380.

Prodromakis T and Papavassiliou C (2009) Engineering the Maxwell-Wagner polarization effect. Applied Surface Science 255(15): 6989-6994.

Ranade R, Zhang J, Lynch J and Li VC (2014) Influence of micro-cracking on the composite resistivity of engineered cementitious composites. Cement and Concrete Research 58: 1-12.

Redon C, Li VC, Wu C et al. (2001) Measuring and modifying interface properties of PVA fibers in ECC matrix. Journal of Materials in Civil Engineering ASCE 13(6): 399-406.

Reynolds JA and Hough JM (1957) Formulae for dielectric constant of mixtures. Proceedings of the Physical Society Section B 70(8) 769-775

Saraireh D, Walls S, Suryanto B, Starrs G and McCarter WJ (2017) The influence of multiple micro-cracking on the electrical impedance of an engineered cementitious composite. In Strain-Hardening Cement-Based Composites (Mechtcherine V, Slowik V and Kabele P (eds)). Springer, Dordrecht, the Netherlands, pp. 292-299. 
Schneider CA, Rasband WS and Eliceiri KW (2012) NIH Image to ImageJ: 25 years of image analysis. Nature Methods 9(7): 671-675.

Schwan HP, Schwarz G, Maczuk J and Pauly H (1962) On the low-frequency dielectric dispersion of colloidal particles in electrolyte solution. Journal of Physical Chemistry 66(12): 2626-2635.

Schwarz G (1962) A theory of the low-frequency dielectric dispersion of colloidal particles in electrolyte solution. Journal of Physical Chemistry 66(12): 2636-2642.

Shi ZQ and Chung DDL (1999) Carbon fiber-reinforced concrete for traffic monitoring and weighing in motion. Cement and Concrete Research 29(3): 435-439.

Soga K (2018) Whole life sensing of infrastructure. In Developments in Earthquake Geotechnics (Iai S (ed.)). Springer, Cham, Switzerland, vol. 43, pp. 111-130.

Spencer BF Jr., Park JW, Mechitov KA, Jo H and Agha G (2017) Next generation wireless smart sensors toward sustainable civil infrastructure. Procedia Engineering 171: 5-13.

Starrs G and McCarter WJ (1998) The immittance response of cementitious binders during early hydration. Advances in Cement Research 10(4): 179-186, https://doi.org/10.1680/adcr.1998.10.4.179.

Suryanto B, Wilson SA, McCarter WJ and Chrisp TM (2015) Self-healing performance of engineered cementitious composites under natural environmental exposure. Advances in Cement Research 28(4): 211-220, https://doi.org/10.1680/jadcr.15.00022.

Suryanto B, McCarter WJ, Starrs G and Ludford-Jones GV (2016)

Electrochemical immittance spectroscopy applied to a hybrid PVA/steel fiber engineered cementitious composite. Materials \& Design 105: 179-189.

Suryanto B, Tambusay A and Suprobo P (2017a) Crack mapping on shear-critical reinforced concrete beams using an open source digital image correlation software. Civil Engineering Dimension 19(2): 93-98, https://doi.org/10.9744/ced.19.2.93-98.

Suryanto B, McCarter WJ, Starrs G and Chrisp TM (2017b)

Characterization of fly-ash using electrochemical impedance spectroscopy. Procedia Engineering 171: 705-714.

Suryanto B, Buckman JO, McCarter WJ and Taha H (2018a) In situ dynamic WetSEM imaging and electrical impedance measurements on Portland cement during early hydration. Materials Characterization 142: 86-100.

Suryanto B, Takaoka H, McCater WJ, Saraireh D and Taha H (2018b) Impedance measurements on an engineered cementitious composite: A critical evaluation of testing protocols. Measurement 129: $445-456$.

Tambusay A, Suryanto B and Suprobo P (2020) Digital image correlation for cement-based materials and structural concrete testing. Civil Engineering Dimension 22(1): 6-12.

Wansom S and Kanokkanchana K (2017) Electrical impedance response for physical simulations of composites with conductive fiber-bridged insulating cracks. Journal Materials Science 52(17): $10023-10037$.

Wen S and Chung DDL (2003) A comparative study of steel-and carbon-fibre cement as piezoresistive strain sensors. Advances in Cement Research 15(3): 119-128, https://doi.org/10.1680/adcr.2003. 15.3 .119

Yang P, Chowdhury S and Neithalath N (2018) Strain sensing ability of metallic particulate reinforced cementitious composites: experiments and microstructure-guided finite element modelling. Cement \& Concrete Composites 90: 225-234.

Yoo DY, You I, Zi G and Lee SJ (2019) Effects of carbon nanomaterial type and amount on self-sensing capacity of cement paste. Measurement 134: 750-761. 